\title{
The determinants of Facebook social engagement for National Tourism Organisations' Facebook pages: a quantitative approach
}

Article

Accepted Version

Creative Commons: Attribution-Noncommercial-No Derivative Works 4.0

Mariani, M. M., Mura, M. and Di Felice, M. (2018) The determinants of Facebook social engagement for National Tourism Organisations' Facebook pages: a quantitative approach. Journal of Destination Marketing \& Management, 8. pp. 312-325. ISSN 2212-571X doi: https://doi.org/10.1016/j.jdmm.2017.06.003 Available at https://centaur.reading.ac.uk/74561/

It is advisable to refer to the publisher's version if you intend to cite from the work. See Guidance on citing.

To link to this article DOI: http://dx.doi.org/10.1016/j.jdmm.2017.06.003

Publisher: Elsevier

All outputs in CentAUR are protected by Intellectual Property Rights law, including copyright law. Copyright and IPR is retained by the creators or other copyright holders. Terms and conditions for use of this material are defined in the End User Agreement. 


\section{www.reading.ac.uk/centaur}

\section{CentAUR}

Central Archive at the University of Reading

Reading's research outputs online 


\title{
The determinants of Facebook social engagement for National Tourism Organisations' Facebook pages: A quantitative approach
}

\begin{abstract}
This work explores how the National Tourism Organizations (NTOs) of the top 10 most visited countries by international tourists strategically employ Facebook to promote and market their destinations. Based on big data retrieved from the NTOs' Facebook pages, and leveraging advanced metrics for capturing user engagement, the study sheds light on the factors contributing to superior level of social activity. The findings indicate that the way Facebook is tactically employed varies significantly across sampled NTOs. The panel data regression analyses suggest that engagement is positively affected by posting visual content (namely photos), and posting during the weekends, and negatively affected by evening posting. Post frequency displays no statistically significant effect on social engagement. The study also shows that most of the NTOs (except for Italy, Spain, Turkey and the UK) deploy Facebook with a top-down approach, and spontaneous user generated content (UGC) is allowed to a very little extent.
\end{abstract}

Keywords: Social media, Facebook, Big Data, National Tourism Organizations, engagement, destination marketing, country destinations, panel data multivariate regression analyses 


\section{Introduction}

Over the last 50 years technology developments in transportation, the increase of disposable income to be allocated to travels, the improvement of security and rights for tourists, as well as the intensifying processes of globalization, have significantly contributed to expand the market for travel and tourism activities (UNWTO, 2015).

In the 1980s, European tourism destinations held almost $63 \%$ of the market share for international tourism (UNWTO, 2014). This share has progressively declined to 51\% in 2010 and is projected to further decrease to $41 \%$ by 2030 (UNWTO, 2015) while destinations in Asia and Pacific, Middle East and Africa are gaining in terms of their relative shares. Moreover, in 2015 emerging economy destinations have surpassed advanced destinations in terms of international tourist arrivals. The overall picture drawn so far clearly suggests that competition among tourism destinations is escalating (Mariani, Buhalis, Longhi \& Vitouladiti, 2014) and Destination Management Organizations (DMO) at any level (national and local) should find (new) ways to promote themselves effectively in the global hypercompetitive arena (D’Aveni, 1994).

Interestingly, the introduction, penetration and consolidation of the Internet over the last three decades and Online Social Networks (OSNs) over the last decade have brought about a digital revolution in travel and tourism, disrupting extant business models and introducing new ones, thus deeply modifying the way tourism destinations (and companies) promote and market themselves.

Information and Communication Technologies (ICTs) have played a crucial role in expanding the industry worldwide on one hand, while at the same time have offered cost effective tools for any destination to promote itself and therefore have reinforced competitive trends among destinations themselves.

In addition to empowering consumers, ICTs provide 'effective tools for suppliers to develop, manage and distribute their offerings worldwide' (Buhalis \& Law, 2008: p. 610). While at the beginning of the commercial exploitation of the Internet, information was published by an organization or company and interaction did not exist, today OSNs such as Facebook, Twitter and Instagram and review sites such as Tripadvisor have created spaces of conversation between organizations and individuals (Boyd \& Ellison, 2008) and new markets dominated by the paradigm of an economy revolving around social media, i.e., a 'socialnomics' (Qualman, 2009).

OSNs allow Internet users to collect information, build and develop relationships, make travel related decisions, share travel experiences, and eventually rate tourism services and providers (Ayeh et al., 2013; Stepchenkova et al., 2007; Visani et al, 2016; Wang et al, 2002; Wang \& Fesenmeier, 2004). 
OSNs bring consumer-generated content (CGC) to life: photos, videos, blogs and reviews are posted and uploaded every fraction of a second worldwide (Sigala et al., 2012; Wenger, 2008) and are widely used by online travellers (Bilgihan et al., 2016; White \& White, 2007), thereby allowing users rather than organisations to take charge of Internet content (Schegg et al. 2008). CGC and online reviews might undermine the reputation of established organizations and brands (Dijkmans et al., 2015; Gretzel, 2006; Shea et al., 2004).

Consequently, DMOs at both the national and local level should pay attention to how they use social media, as this can play a crucial role in effectively promoting and marketing a tourism destination in a global highly competitive context (Baggio et al., 2014; D’Aveni, 1994; Mariani \& Baggio, 2012).

This paper is one of the outputs of a wider research project carried out by a multidisciplinary research team investigating how DMOs at different levels of government use social media (more specifically Facebook) to promote and market their destinations, with a specific focus on the determinants of social engagement. As such, it is a further extension and validation of the study conducted by Mariani et al. (2016).

The manuscript contributes to the extant body of 'e-tourism research' (i.e., research at the intersection between tourism and ICTs) with a focus on digital destination marketing, from a number of perspectives. First, it adds to the currently scant stream of empirically based studies that investigate DMOs' social media marketing from a quantitative perspective (Hays et al., 2013; Mariani et al., 2016). Specifically, it explores how the National Tourism Organizations (NTOs) of the top ten destination countries in terms of international tourist arrivals deploy OSNs -- and specifically Facebook -- to promote and market their destinations, illustrating their varying degrees of social-media usage. Second, in line with previous literature (Mariani et al., 2016), this work identifies and measures the drivers of increased levels of social activity by means of multivariate regression analyses based on a panel dataset specifically developed for this research project. Finally, a few managerial best practices are identified that NTOs can adopt in their use of Facebook.

The paper is organised as follows. Section 2 provides a review of relevant literature on destination marketing and social media for digital destination marketing. Section 3 illustrates the methodology that was employed. Section 4 reports the research findings and the analysis. Finally, Section 5 discusses both the managerial and policy-making implications of this analysis, describes its limitations, and offers avenues for future research. 


\section{Destination marketing and online destination marketing}

\subsection{Destination marketing}

Globalization in travel and business, technology development, and increase of income allocated to travel, have intensified competition between tourism destinations and companies. In this context, destinations are challenged to find new ways to be competitive by providing, managing and marketing positive and memorable tourist and visitor experiences (Mariani \& Giorgio, 2017; Pike \& Page, 2014; Pine \& Gilmore, 1998) and building strong destination brands (Blain et al., 2005).

Historically they have established starting from the nineteenth century Destination Management Organizations (DMOs) at various level of government (local, regional, national). Pike and Page (2014) in their accurate chronological account of DMOs, highlight that the first regional tourism organisation (RTO) was established in Switzerland at St. Moritz in 1864 (Läesser, 2000), and starting from 1879 municipal promotion was supported by a property tax at Blackpool, England (Walton, 1991). The USA saw the creation of the first convention and visitors' bureau (CVB) at Detroit in 1896 (Ford \& Peeper, 2007; Gartrell, 1992; Ward, 1995). Afterwards, in 1901, the first world's first national tourism office (NTO) was established in New Zealand (McClure, 2004; NZTPD, 1976). The number of DMOs increased dramatically during the post-war period with many establishing their core marketing role in the 1960s and 1970s (Laws, 1997).

Interestingly and mirroring the proliferation of DMOs, the destination marketing literature started developing in the early 1970s (Pike \& Page, 2014), with the study field been characterised by 'a fragmented applied research approach rather than theory building' (Pike \& Page, 2014: p. 203).

A further wave of DMOs' setting up took place over the 1980s-1990s and brought to a population exceeding 10,000 worldwide according to McKercher (see Pike, 2008). Today there is a certain degree of consensus on the fact that destination marketing research deals with the application of theories and techniques to identify and contribute towards solving marketing management decision problems for a destination or a city (Malhotra, 1996) that are typically carried out by Destination Management Organizations (DMOs)

The role played by DMOs at different levels of government (nation, state, and municipality) for the competitiveness of their destination has been analyzed in depth by Pike and Page (2014). They underline the relevance of DMOs in the current turbulent environment (Ashworth \& Page, 2011; Pike \& Page, 2014) even though they note that DMOs frequently can at best influence marginally the competitiveness of a tourism destination. While DMOs cover not only marketing activities but also other roles such as leadership and coordination, planning and research, product development, partnership and team-building, and community relations (DCG, 2012; Morrison, 2013), 
for the purposes of this paper we focus on digital destination marketing that we review in the following subsection.

\subsection{Online destination marketing}

Over the last fifteen years and looking back from the time of writing an increasing attention has been paid to online (or digital) destination marketing (Buhalis \& Foerste, 2015; Fesenmaier et al., 2003; Gretzel et al., 2000; Mariani et al., 2014a, 2014b; Marine-Roig \& Anton Clavé, 2015; Zhou, 2014;) within the wider area of eTourism research (Buhalis \& Law, 2008), sometimes with the development of empirical multi-country and international comparative analyses (Feng et al., 2003). In a number of cases social media marketing -- to be intended as a way to reduce the gap between organisations and customers/users (Borges, 2009) -- has been analysed as one of the 'mega trends' impacting significantly the tourism system (Chung \& Buhalis, 2008; Leung et al., 2013).

For instance, Hays et al. (2013) have analysed the use of social media as a destination marketing tool by national tourism organizations. More specifically, they carried out a content analysis of the Facebook and Twitter accounts on the top 10 international tourism destinations as indicated by the United Nations World Tourism Organization (UNWTO) Tourism Highlights 2010 Edition. In their exploratory study, after narrowing down the sample to seven tourism boards' official Facebook pages and Twitter accounts, they analysed the content posted on the aforementioned OSNs in the month of June 2011. The results from the content analysis as well as the findings from semi-structured interviews illustrated that the social media strategies of top DMOs varied considerably, and with the exception of the efforts of VisitBritain and Tourism Queensland, were largely rudimentary and experimental. More specifically, the two cases of VisitBritain and Tourism Queensland seemed to offer many examples of best practices for other national tourism organizations (NTOs) starting to enter the world of social media to market their destination to learn from. Three key findings emerged from the study: first, the majority of the DMO analysed were not deploying social media to their full effectiveness in terms of interaction and engagement with consumers. Secondly, social media were often underfunded and/or neglected, as they were not recognized as a vital tool in marketing strategies. Third and last, the authors suggest that NTOs should become more innovative and creative in their social media strategies to differentiate digital marketing from traditional marketing methods. Hays et al. (2013) also emphasized that a destination's ranking on tourist arrivals does not dictate a more developed social media strategy, as less visited destinations could be more active and innovative in their social media efforts.

Mariani et al. (2016) have examined the use of Facebook by the twenty Italian regional DMOs. Based on big data analysis from the regional DMOs' Facebook pages and improved metrics for capturing user engagement, supplemented with semi-structured interviews conducted with DMOs' 
managers, the authors identify the factors contributing to superior level of social activity. They find that the way Facebook is tactically and strategically employed varies significantly across Italian regional DMOs. More specifically, by using a multivariate regression model they point out that visual content (namely photos) and moderately long posts have a statistically-significant positive impact on DMOs' Facebook engagement, whereas high post frequency, and early daily timing (in the morning) of posts have a negative impact on engagement. They also indicate that most of the regional DMOs (except for Trentino, Tuscany, and Sicily) deploy Facebook with a top-down approach, and spontaneous user generated content (UGC) is allowed to a very little extent. Managerial best practices identified include creating opinion polls, games, quizzes, and contests involving visual content (e.g., to select the cover photo of the Facebook page). They note that smaller DMOs have only recently realised the importance of social media strategies and prioritised investments in social media and in the professional development of the digital marketing staff: however, for them social media marketing is still severely underfunded.

Overall, the studies reviewed above reveal that digital marketing in general and social media marketing in particular are increasingly adopted by DMOs, but often with an experimental approach and with many differences across DMOs in the way investments in social media are made and how the role of social media is interpreted and made sense of.

However, it seems that a number of DMOs are realizing the importance to manage effectively social media to achieve sustained competitive advantage for their destinations (Mariani et al., 2014a; Pike \& Page, 2014). This is becoming more and more relevant due to two major factors: on one hand the huge uncertainty which characterizes today the economic and business landscape and, on the other, the public austerity manoeuvres that are drastically reducing funding for DMOs at both the national and regional levels. These factors are pushing many DMOs to turn to social media as a relatively low-cost marketing tool with a global reach. Despite these trends, research on the use of Web 2.0 and social media as destination marketing tools remains relatively scant (Feng et al., 2003; Hays et al., 2013; Mariani, 2016; Stankov et al., 2010; Xiang \& Gretzel, 2010). Moreover, the studies conducted on NTOs suffer from a number of methodological limitations, i.e., short timeframes, small sample size, outdated data (Hays et al., 2013), and absence of solid metrics to capture social engagement.

To bridge these research gaps, we carried out a study with the following main objectives: (1) to explore how NTOs of selected country destinations strategically employ Facebook to market their destinations; (2) to illustrate the varying degrees of Facebook usage among the studied NTOs; (3) to determine what factors contribute to increased engagement of tourists/users through a statistical analysis; (4) to identify several cases of good practices in the use of Facebook by NTOs. 
Consistently with previous studies (Mariani et al., 2016), we decided to focus on Facebook, rather than on other social media, because Facebook is by far the most-used social media platform among NTOs and the most popular worldwide, with more than 1,6 billion monthly active users (Facebook, 2016).

\section{Methodology}

This study investigates the nature and the degree of Facebook usage by the NTOs of the top 10 international tourism destinations as indicated by the United Nations World Tourism Organization (UNWTO) Tourism Highlights 2015 Edition. The ranking includes (in descending order by tourist arrivals) the following countries: France, United States, Spain, China, Italy, Turkey, Germany, United Kingdom, Russian Federation, Mexico (UNWTO, 2015).

In the footsteps of Hays et al. (2013), the rationale behind choosing the top 10 international destinations is that these destinations have in most cases well-established, national level DMOs in place. These DMOs have been marketing their countries, and cities, regions, and attractions over a long time period and some have adopted digital marketing strategies and tools, and more specifically social media marketing platforms such as Facebook, Twitter and Instagram.

The selection of countries and of the Facebook accounts however, presented several issues that were explored in a pilot study whose findings are described below in the section related to the sampling process.

\subsection{Sampling process}

Industry reports, specialist press releases, and other data from publicly available documents off and online were used to gain a better understanding of the way NTOs strategically use social media. Moreover, two pilot open-ended interviews with online destination marketing experts were conducted (Gioia et al., 2013). This preliminary exploration of secondary data matched with interviews allowed us to appreciate how NTOs' destination marketers make sense of social media. In fact, even though NTOs employ a number of social media platforms (such as Twitter, Youtube, Google Plus, Instagram, etc.) Facebook--with 1.59 billion monthly active users worldwide at the beginning of 2016 -- still appears to be the one most widely adopted by NTOs.

Based on those secondary data and extant literature in the tourism marketing field, we selected Facebook as the appropriate data source for this study and thus collected data from the Facebook pages of all the NTOs. While it is true that in many country destinations the leading role in destination marketing is played by DMOs at lower levels (states in federal systems or regions or even municipalities), still NTOs are investing considerable amounts of money in promoting their destinations both off and online. For instance, Brand USA has significantly invested in digital initiatives including a further development of their 
Facebook presence with the original Facebook account named 'Discover America' transformed into 'Visit the USA'.

Although every NTO under consideration has an official website, the way they are present on the Facebook OSN varies across NTOs. For instance, at the moment when the analysis was carried out, France displayed 24 accounts targeting different geographic markets, Germany showcased 13 different Facebook pages, etc.

Since our objective was to analyse the most visited and socially active Facebook pages, we conducted a pilot study on all the Facebook pages/accounts that allowed us to gain insights to inform our sampling process which consists of two steps, allowing us to generate two sub-samples.

In the first step, we realized that the Facebook page in the country's language and its first international counterpart (typically the English one for non-English-speaking countries) were the most popular in terms of posts and social activity. Thus we created a subsample of 15 Facebook accounts representative of the overall population: 2 accounts for France; 2 for the United States; 2 for Spain; 2 for China; 1 for Italy; 1 for Turkey; 2 for Germany; 1 for the United Kingdom; 1 for Russia; 1 for Mexico.

In the second step, we narrowed down further the sample to take into account the following issues:

1. The Russian account displayed negligible social activity and, despite the fact that it was open, no posts at all could be found. In Russia Facebook ranks below local sites such as Vkontakte.ru, ranked first and Odnoklassniki ranked second (Fotis et al, 2011);

2. The Chinese accounts were not taken in consideration due to the fact that they are apparently not managed by the mainland Chinese NTO and Facebook is blocked in the country (except for the Shanghai Free Trade Zone in mainland China, and Hong Kong and Macau);

3. The US accounts have gained attention only very recently and mostly related to the Brand USA campaigns. Considering only the Brand USA accounts would have biased (and underrepresented) the social media marketing activities for the country destination as each individual confederate state markets and promotes itself;

4. The timings of posting and the social activity on the international pages were not consistent with the timings of posting and social activity of the domestic pages. Moreover, for international accounts it was particularly problematic to standardize the timings, being most of the accounts managed by social media teams located in different time zones. Consequently, we only considered the domestic pages of the account.

The two-step sampling process therefore led to exclude the accounts of Russia, China, the USA and the international accounts. This allowed us to create a final subsample consisting of the following seven 
accounts: France Domestic, Germany Domestic, Italy (has only one account), Mexico (has only one account), Spain Domestic, Turkey (has only one account), United Kingdom.

Interestingly, the Germany NTO's domestic Facebook page was the very first one to open: it was created eight years ago in 2008. By February 2014 also the most recent Turkey NTO's Facebook account was opened.

\subsection{Data gathering: Facebook data}

We collected data from the fifteen NTOs' Facebook pages of the first subsample. More specifically, we gathered information on the number and types of posts published on NTOs' Facebook pages, and on the user responses generated by these posts. The data retrieval, aggregation, and analysis were performed leveraging an extant software tool built on cutting-edge technologies for managing data retrieved from the Facebook platform (Mariani et al. 2016).

We extracted the overall population of posts (including the related 'Likes', 'Shares' and 'Comments') present on the Facebook pages of our sample over a 29 months period: August 2013 - December 2015, obtaining a total of 27,502 posts. The contents of those posts were analysed using measures adapted from Hays et al. (2013) and Mariani et al. (2016).

Add Table 1 about here

Furthermore, based on Schetzina (2010) and Frick (2010), we calculated a number of metrics to assess engagement: generic engagement, brand engagement, and user engagement (see Table 2 for details).

Add Table 2 about here

Drawing on previous literature (Mariani et al., 2016), we also computed those same measures of engagement on a rolling basis, in a two- and seven-day time window after the posting date. These rolling metrics were based solely on the 'Comments' and did not include 'Likes' and 'Shares', for which we did not have an exact timestamp.

Finally, we included three additional metrics of engagement that only take in consideration user activity, without normalising it by the number of fans (see Table 3 for details). In this manner, we sought to deal with one of the major shortcomings of the normalised engagement measures usually adopted in the 
literature (Oviedo et al., 2014), whose value over time tends to decrease as the number of fans (in the denominator) increases (Socialbakers, 2015).

Add Table 3 about here

Based on previous literature in the field (Mariani et al., 2016), the aforementioned metrics of engagement were calculated by applying different weightings to Likes (weight $=20 \%$ ), Shares (weight $=30 \%$ ) and Comments (weight $=50 \%$ ). These differential weights are a proxy for the degree of involvement implied by the underlying activities of respectively liking, sharing, or commenting.

\subsection{Data analysis and hypotheses}

In order to explore the main determinants of users' engagement in social media activity, the collected data were analysed using descriptive statistics, and panel data multivariate regression analyses, which certainly represent a methodological advancement compared with previous analyses (Hays et al., 2013; Mariani et al., 2016). As a matter of fact panel data analysis allows us to explain both cross sectional variance among countries and longitudinal variance within the same country over time, thus providing more reliable results compared to standard cross sectional OLS regressions (details on panel data analysis are provided below).

In light of the findings and research gaps identified in extant studies (Hays et al. 2013; Mariani et al., 2016) and to test whether the findings of Mariani et al. (2016) could be generalized to NTOs, our research aims to test the following research hypotheses:

H1: The type of posts made by an NTO has an impact on engagement; more specifically, visual types of posts (such as photos) have a positive impact on engagement

H2: The frequency of posting by an NTO does not affect engagement

\section{H3: Evening posts by an NTO have a positive impact on engagement}

H4: Weekend posts by an NTO have a positive impact on engagement

Our hypotheses were validated using multivariate regressions that account for the multilevel structure of our panel data, which considers each country-level multiple observations over time. Panel datasets show several advantages over conventional cross-sectional or time-series datasets (Hsiao, 2003). Panel data usually give the researcher a larger number of data points, increasing the degrees of freedom and reducing the collinearity among explanatory variables-hence improving the efficiency of statistical 
estimates. Additionally, datasets that combine longitudinal and cross-sectional data allow a researcher to analyse research questions that cannot be addressed using cross-sectional or pure time-series data.

Our analyses used both fixed- and random-effects models. Fixed-effects (FE) analyse the impact of variables that vary over time, while random-effects (RE) also explore differences across observations. In order to assess whether FE or RE should be used, a Hausman test can be applied where the null hypothesis is that the preferred model is random effects vs. the alternative fixed effects (Greene, 2003). Hausman basically tests whether the unique errors are correlated with the regressors - the null hypothesis is they are not.

The following variables were included in the model: Engagement was used as the dependent variable, regressed against Photo, Post frequency, Morning posts, Evening posts, Night posts, Week-end posts used as independent variables.

\section{Analysis and results}

Over the 29 months period August 2013 - December 2015, the larger sample of 15 Facebook accounts of selected NTOs recorded a total of 27,502 posts. However, for the reason explained in the 'Sampling process' section we focused on the smaller sample of 7 Facebook accounts which displayed 20,221 posts $(73.5 \%$ of the larger sample), of which 7601 (37.6\%) were made by the NTOs themselves (Table 4). The latter percentage suggests that the goal of two-way communication between NTO managers and fans has been achieved for the selected accounts, given that two thirds of the posts is generated by users. The leader in terms of total posts was the Italian NTO page, followed by Spain Domestic and Germany Domestic. Italy also had a very high percentage of posts by users, as did Spain and Germany.

Add Table 4 about here

Overall it seems that European NTOs (see Italy, Spain and Germany) are more active on their Facebook platforms and also those whose users generate more content.

If we now look only at the posting activity of the NTOs themselves (excluding that of users), the general results do not change much, and the leaders now are Spain, Italy and Turkey. The countries with the highest percentage of posts by users are Italy, Spain and Germany: these are the countries whose users post more actively.

The reason behind the sampling process described in section 3.1 are very clear if we consider that the 7 
accounts of our quantitative analysis generate most of the social activity of the wider sample of 15 accounts. Indeed they generated $17,413,598$ Likes $(95.1 \%$ of the total number of Likes generated for the 15 accounts) and 2,609,562 Shares $(96.9 \%$ of the total number of Shares generated for the 15 accounts) and 362,216 Comments $(88.4 \%$ of the total number of Comments generated for the 15 accounts):

Add Tables 5.a and 5.b about here

Interestingly enough the social activity (in terms of Likes, Shares and Comments) is much higher (with a multiplicative factor of 10) than that detected in a previous study analysing Facebook activity for DMOs (Mariani et al., 2016), despite the sampled posts in this study is lower (27,502 posts vs. 33,597). This might be due to the fact that the referenced study was considering just one year (2013), while this research includes 29 months (August 2013 - December 2015) and perhaps captures also an increase of social media activity which is the outcome of users becoming more social media oriented over time.

If we focus on user activity (see Table 5.b), we find that the UK, Turkey and Italy are the leading NTOs in terms of Likes (with 5,070,838; 4,541,343; and 3,114,870 Likes respectively) while at the bottom of this ranking is France (with 228,942 Likes). The top 3 NTOs in terms of Likes are also those that lead the ranking for Comments (United Kingdom, Italy and Turkey with 105,654; 79,099; and 67,571 Comments respectively), while at the bottom of this ranking we again find Germany (with 7029 Comments respectively). Finally, the top 3 NTOs in terms of Likes and Comments are also those that lead the ranking for number of Shares (Italy, UK and Turkey with 820,588; 647,937; and 533,333 Shares respectively), while among the worst performers we find France (with 30,241 Shares).

Examining the last 4 columns of Table 5.b, it is clear that the majority of Comments and Shares is generated by users. Strangely of the top 3 NTOs in terms of user activity only one (Italy) ranks high in terms of number of posts. Therefore, unlike previous research (Mariani et al., 2016) it appears that high posting activity (in terms of number of posts) on a NTO Facebook page does not necessarily coincide with high user activity.

With a few exceptions most of the Likes, Shares and Comments originate from users (i.e., the NTO engages in posting activity but is rarely involved in liking/sharing/commenting activities).

If we concentrate on our final sample of 7 NTOs, most of the content posted by NTOs includes photos $(89.7 \%$ on average for the overall population over the period 2013-2015), followed by links 
$(5.2 \%)$ and videos (4.4\%). The content-type breakdown for each NTO is presented in Figure 1:

Add Figure 1 about here

Italy, France and Spain are the countries whose NTOs have the strongest preference for posting photos, as well as being among those that post most actively in general.

Interestingly, although Mexico and the UK have a similar number of posts made by the NTO (see Table 4), the UK users tend to interact more (by commenting, liking, and sharing more items). This may be ascribable to the higher loyalty of UK users, resulting from that NTO's adoption of best practices (that are emerge from the quantitative analysis and will be further validated once the interviews will be taken to completion). Figure 2 visually illustrates the situation across NTOs.

Add Figure 2 about here

The NTO's Facebook sites that had the highest number of fans at the end of 2015 (UK, Mexico and Turkey) are mostly the same as those with the highest numbers of Likes, Shares, and Comments--with the exception of Italy which, despite its modest fan base (one tenth of the other three NTO's fan bases), displays significant social media activity. However, as is clear from Table 6, the largest percentage increases over the course of 2013 occurred for the Turkish NTO which in 1.5 years almost reached the leading NTOs.

Add Table 6 about here

\subsection{Active users and engagement metrics}

The descriptive statistics reported thus far do not include a proper assessment of user activity. In fact, the users totalled above may be active or inactive. Figure 3 shows that 
the number of active users (defined as those who posted at least one comment over the period 2013-2015) is far less than the total number of fans for each NTO page. This suggests that the fan base of a NTO page is not a reliable normalisation variable to be used for computing engagement metrics.

Add Figure 3 about here

Interestingly, while Spain is the most active NTO in posting, it is in a middle position as far as number of active users are concerned.

Looking more in depth at the distribution of the number of comments made by active users, a significant finding emerges-- on average, almost $93 \%$ of active users (i.e., users who posted at least 1 comment during the year), posted less than 5 comments in total over the period 2013-2015 (Figure 4).

Add Figure 4 about here

Italy shows the highest percentage of 'repeat users'--meaning users who intervened more than once in threads initiated by the NTO. This might partially explain why the Italian NTO is the second NTOs in terms of number of comments (see Tables 5.a and 5.b). Technically, we might hypothesize that the active users of the Italian NTO page show strong loyalty. The reasons for this are partially explained in Section 4.3.

Turning now to focus on the engagement metrics, we find that for generic and brand monthly engagement metrics (Figure 5), NTOs such as Turkey, France, and Italy display the highest values.

Add Figure 5 about here

If we assess the level of activity linked to each individual post and do not normalise it by the fan base (but only by the posts by users), as suggested in the most recent literature (Oviedo et al., 2014), the results of the analysis change slightly: UK, Turkey and Italy become the top performers in terms of engagement (Figure 6). 
Add Figure 6 about here

These engagement results seem a more adequate proxy for capturing the actual involvement of users, and are consistent with the results shown in Table 5.b and Figure 2.

If we refine the metric even further, so that engagement is normalised neither by fan base nor by number of posts, the results become closer to those of the preceding figure (Figure 6) and more consistent with those obtained from Table 5.b and Figure 2:

Add Figure 7 about here

The NTOs with the highest values of 'user' and 'user-to-DMO' interaction are UK, Turkey and Italy (see Figure 7). Interestingly, 'user-to-user' interaction is instead extremely low, suggesting that posts written by users do not attract the attention of other users, often because they are in plain text (they do not include photos, videos, etc.). In some cases (i.e. UK, Mexico and Turkey), the 'user-to-user' interaction is even not present, since users are not authorized to write their own posts in the Facebook profile of the NTOs. This result also seems to indicate that NTOs still deploy social media in a traditional top-down fashion, rather than exploring ways to foster a bottom-up UGC-driven approach. This might simply be because UGC is on average less interesting and 'professional' than content generated by the NTOs.

In the footsteps of Mariani et al. (2016), the engagement metrics were computed applying an innovative scheme to differentially weight Comments, Shares, and Likes. To ensure methodological accuracy, we conducted a robustness check by using different weights and found that different weight settings generated different absolute values of user engagement, but did not alter the ranking of NTO Facebook pages in terms of engagement.

\subsection{Factors influencing user activity and user engagement}

In this section, we focus on the determinants of engagement and analyse them separately. More specifically, we consider the overall population of posts generated by the sampled NTOs over the period August 2013 - December 2015 and analyse how they relate to the following variables: a) type of 
post; b) length of the post; c) posting time of day; d) posting day of the week; e) posting month of the year; f) frequency of posting.

Type of post. As noted previously, most of the sampled NTOs tend to post mainly photos. Our analysis shows that photos and videos are also the type of content that elicits most comments (Figure 8).

Add Figure 8 about here

Length of post. The analysis on the overall population of posts shows that the majority of them are between 150 to 350 characters long, with posts of around 200 characters being the most frequent (they appear in $40 \%$ of cases):

Add Figure 9 about here

In contrast with previous literature (Mariani et al., 2016) it is not clear the relationships between the length of the post and engagement, with a kind of bimodal distribution wherein posts around 100 characters in length and post around 600 characters generating the peaks of engagement (Figure 10).

Add Figure 10 about here

Posting time of day. The analysis on the overall population of posts also shows that the majority of sampled NTOs posts are made in the morning or afternoon (ordinary working hours), although several also post in the evening.

Add Figure 11 about here

Contrarily to previous evidence (Mariani et al., 2016) content posted in the evening seems to have a negligible positive effect on generic engagement if compared with content posted in the afternoon. 
Perhaps NTOs prefer to post in the afternoon and get an immediate reaction in the afternoon soon after posting (see Figure 12) or simply this result is not consistent with previous findings because we are considering a number of different countries together rather than just multiple regions within a country.

Add Figure 12 about here

Posting day of the week. The analysis shows that the majority of NTO posts are made during the working week (Monday to Friday), with just 26.5\% of DMO content being posted during the weekend.

It is difficult to identify a clear-cut relationship between the day of the week when content is posted and the resultant engagement. That said, it does seem that content posted on Thursdays, Fridays and Saturdays elicits higher engagement (Figure 13).

Add Figure 13 about here

It appears that DMO posting activities and the responses to those posts by users are asymmetric: DMOs post mainly during the working week whereas users interact more during the weekend.

Frequency of posting. Forty-nine percent of our sample of posts is posted with a low frequency (one post per day and less than a post per day) while a small percentage of our sample is posted with high daily frequency (in this case NTOs post 6 posts per day) (Figure 14).

Add Figure 14 about here

The effect of posting frequency on engagement is illustrated in Figure 15, which shows that maximum engagement occurs when the daily frequency is around 4. In other words, there seems to exist an optimal level of frequency of posting to generate engagement. This seems to a certain extent in contrast with previous findings that emphasized that the less is posted, the highest would be the engagement (see Mariani et al., 2016). 
Add Figure 15 about here

Posting month of the year. The empirical analysis shows that NTOs post the most during the months of June and July, whereas activity is lowest in January and December.

Engagement, on the other hand, is highest in July, when it reaches a peak. Generally, there seems not to be any clear-cut relationship between the month of posting and the engagement metrics.

The variables presented in this section are summarised in Table 7, which also shows the correlation between these variables and engagement.

Add Table 7 about here

Based on the observations made thus far, concerning the relationships between individual variables and engagement, we tested the hypotheses presented in section 3.3.

Given that the Hausman test suggests that a FE model provides better estimates for our data than a RE model (chi2(6)=1956 $\mathrm{p}<.001$ ), then Table 8 reports the results of the panel data regression analyses using a FE model. Table 8 shows the results of the regression analysis.

Add Table 8 about here

The proposed model was found to have a good fit, explaining $16 \%$ of the within variance and 14\% of the between variance. Considering the proposed hypotheses: $\mathrm{H} 1$ cannot be rejected (with 5\% statistical significance); H2 cannot be rejected, as the effect of post frequency on engagement is not statistically significant. H3 likewise cannot be rejected (with $5 \%$ statistical significance) however the effect of the relationship evening posts on engagement is negative. Finally, $\mathrm{H} 4$ cannot be rejected (with $5 \%$ statistical significance).

The regression results thus suggest that engagement is positively affected by posting Photos $(\mathrm{p}<.05)$, and by posting during the weekends $(\mathrm{p}<.05)$, and negatively affected by evening posting $(\mathrm{p}<.05)$. The significant link between visual content and engagement confirms that tourists (or potential travellers) who use online social networks are attracted by images of the sights and destinations that 
they have visited or plan to visit. This is consistent with the strong relationship between tourism and image-making media related to sightseeing traditionally featured in tourism studies (e.g. Beeton, 2004), and the fact that NTOs recognize tourists' preference for visual content sharing (Munar \& Jacobsen, 2014). Posting during the weekend also positively affects engagement, possibly because Facebook users are more active at that time. Finally, evening posts negatively affect engagement, probably because users tend to react in a short time to NTOs' social activity that takes place mostly during the afternoon.

Finally, our results show a model fit $\left(\mathrm{R}^{2}\right)$ that is lower than previous results published on similar topics (Mariani et al., 2016). This might be due to the use of panel data analyses compared to cross sectional datasets. Specifically, panel data reduce the magnitude of a key econometric problem that often arises in empirical studies, namely, the often-heard assertion that the real reason of finding (or not) certain effects is the presence of omitted (not effectively measured or unobserved) variables that are correlated with explanatory variables. By utilizing information on both the intertemporal dynamics and the individuality of the entities being investigated, the results presented in this paper better control for the effects of missing or unobserved variables, thus reducing the variance explained by the model.

\subsection{Social media strategies employed by Italian regional DMOs: interaction with consumers and users}

Although at the time of writing we do not have sufficient qualitative evidence to dig deeper into best managerial practices, our quantitative analysis allows us to identify some successful cases of social media activity by NTOs, namely the most successful posts.

Overall, the extensive analysis of posts/contents conducted on the sampled NTOs' Facebook pages, signals that the UK, Turkey and Italy are the NTOs which have posted the most successful contents and that display the highest levels of social engagement (see Figures 6 and 7). Interestingly they are also the accounts with the higher number of active users (see Figure 3).

The most successful post in terms of Likes over the sampled period is a photo posted by the Turkey's NTO on the 17/07/2014. This photo totalled 81,778 likes over the sampled period and is also a further evidence of the fact that professionally edited visual content (namely photos) represent a valid way to attract the attention of Facebook users.

Add Figure 16 about here 
The most successful post in terms of Shares is a video posted by the Turkey's NTO on the 10/11/2014. This video was shared 11,711 times. It is based on engaging and compelling content directed to both visitors and residents and it is based on a video storytelling of the life of Istanbul residents. This professionally shot video became viral in a short time due to its capability to address both residents and visitors in a touching way.

Add Figure 17 about here

The most successful post in terms of Comments is a photo posted by the United Kingdom's NTO on the 24/06/2014. The photo generated 2,285 comments over the sampled period of time. The reason why this photo was so successful is that it managed to engage the users through a compelling game that is repeated weekly.

Add Figure 18 about here

If we concentrate on photos (the most engaging visual content), the two most shared photos were posted respectively by the British NTO on the and the Italian NTO on the 7 March 2014 and on the 17 October 2014. They were shared respectively 8,829 and 7,749 times over the sampled period of time. The former one leveraged the use of unique views matched with engaging questions and texts; the latter one represent the celebration of a landmark event, namely the city of Matera winning the competition for city of culture in 2019 .

Add Figures 19 and 20 about here

Overall, our analysis confirms that the most engaging content is visual (photos and videos) and typically is associated with opinion polls, quizzes, or games. Interestingly, the top 5 photos in terms of shares were posted by the UK NTO (the $1^{\text {st }}$ in the ranking) and Italy (posting photos $2-5$ in the ranking). The top 5 videos in terms of shares were all posted by Turkey. 
Turkey is an emblematic case of how the increasing attention paid to visual content by relatively 'young' NTO Facebook pages can help them in generating high levels of social activity and users engagement.

\section{Conclusions and implications}

The results of this quantitative analysis clearly show that each National Tourism Organizations under consideration is developing its own approach to social media tactics on Facebook. The latter ones might reflect broader social media strategies If we look simply at the engagement data, it is sometimes difficult to determine if higher levels of engagement are the by-product of an experimental use of social media or simply the outcome of a consolidated and systematic tactical approach to social media. Certainly high level of social activities are hint of a successful use of social media for the targeted markets.

However, a few NTOs' accounts are capable of generating a significant amount of social activity due to their continued attention to visual content (e.g., the UK, Italy and Turkey).

Our findings indicate that visual content (namely photos) and week-end posts have a statisticallysignificant positive impact on NTOs' Facebook engagement metrics, whereas late daily timing (in the evening) of posts have a negative impact on engagement. The strong link between visual content and engagement has clearly to do with the power of images in marketing and promotion (Fiore et al., 2005). It echos that a picture is worth a thousand words, especially on Facebook (Vilnai-Yavetz \& Tifferet, 2015) Clearly, the prevalence of images in DMOs posts also shows that DMOs recognise tourists' preference for visual content sharing (Munar \& Jacobsen, 2014). This is consistent also with previous findings (Mariani et al., 2016). Weekend posts boost engagement due to the more significant amount of time that Internet users have to interact on social media during the weekend.

Posting in the evening has a negative impact on engagement and this seems to contradict both statistics on the usage of the Facebook platform and previous findings on a specific national context (Mariani et al., 2016). Perhaps Internet users react to NTOs content either as soon as it gets published in the afternoon or the day after. However, this result needs to be better understood and detailed also in light of disagreement between social media marketers across companies, countries and regions about the optimal time to post.

By looking at the most successful post over the 29 months sampled, we can derive a few empirical observation that might generate managerial implications for NTOs. First, it seems that NTOs of destinations such as the UK, Turkey, and Italy have developed some good practices in the social media arena that could be usefully leveraged by other NTOs. They deploy several digital marketing tactics to enhance engagement such as matching engaging professionally edited visual content (i.e., photos, videos) with opinion polls, games, quizzes, and contests. Our findings suggest that it would benefit 
other NTOs to tactically deploy visual content to elicit their users' engagement. This approach is likely to boost social activity on their pages. Additionally, embedding such visual content in opinion polls or quizzes appears to compel users to share the content and make it viral by creating positive electronic word-of-mouth (Dijkmans et al., 2015; Luo \& Zhong, 2015) which in turn could impact users' travel planning decisions (Ayeh et al., 2013) and the reputation of the destination.

Second, even if our sampling process led us to exclude for a matter of methodological rigour and accuracy a number of NTOs, it seems that European NTOs are doing quite well when it comes to create social engagement. Particularly the newcomer Turkey has been able to generate in just a couple of years a great amount of social activity on its Facebook account.

Third, it seems that only a small number of the NTOs analysed are trying to incorporate social media into an overarching flexible social media marketing strategy, that allows for experimentation and for enhancing engagement and informal conversation. These results seem to corroborate the findings of previous studies on the use of social media by national DMOs (Hays et al. 2013).

Fourth, our empirical evidence seems to corroborate the findings of Hays et al. (2013) who emphasized that a destination's ranking on tourist arrivals does not dictate a more developed social media strategy. Indeed relatively less visited destinations, such as the United Kingdom or Turkey (which are not in the Top 5), could be as active and innovative in their social media efforts as more visited destinations like Italy and Spain (which are among the top 5).

Overall, the aforementioned managerial implications generate a few recommendations for governmental departments dealing directly or indirectly with destination marketing at the national level. First, national governments should pay an increasing attention to the way social media are used across countries as social media certainly represent a potential source of competitive advantage for the destination (Ritchie \& Crouch, 2000) and the country itself (Porter, 1990; Fratocchi et al, 2015). Second and related to the previous point, governments should improve their knowledge of social media marketing practices deployed by their competitors through benchmarking exercises that might be conducted either in-house or by third parties (this latter hypothesis seems the more likely as in many cases NTOs do not seem to be equipped with the necessary skills to undertake accurate measurements). This step is fundamental as it might allow governments to learn best managerial practices in terms of social media tactics and relatedly to better customize their communication and promotional tactics on the social media to target extant markets and develop new ones. Third, it seems that governments might use the business intelligence stemming from social media records and share it with tourism companies to design and develop better tourism products and services based on consumers' preferences revealed in real time by travellers and tourists (Verhoef et al., 2016). This study has a number of limitations. First, the analysis was carried out by selecting the top 10 countries in terms of 
international tourist arrivals but due to several issues, we had to narrow down our sample first to 15 and later to 7 accounts to ensure methodological accuracy, rigour and comparability. Consequently, this study can only be generalised for NTOs with a similar online presence on Facebook and adopting similar social media strategies.

Second, this analysis is only the quantitative part of a wider ongoing research project aiming at understanding how NTOs strategically and tactically use social media to engage their users. At the moment of writing we are conducting a number of semi-structured interviews with social media marketers from the analysed NTOs, in order to inspect the issues that emerged from the quantitative analysis in more depth and reinforce the validity of the findings. The information stemming from those interviews will be used to complement the data obtained from quantitative research and will allow to refine the analysis through data triangulation (Jick, 1979). Finally, future work could expand the time frame of the analysis to include several more years onward and explore other factors generating social engagement. 


\section{REFERENCES}

Ashworth, G., \& Page, S.J. (2011). Urban tourism research: Recent progress and current paradoxes. Tourism Management, 32, 1-15.

Ayeh, J.K., Au, N., \& Law, R,. (2013). Predicting the intention to use consumer-generated media for travel planning. Tourism Management, 35, 132-143.

Baggio R., Czakon, W., \& Mariani, M.M., (eds.), (2014). Managing Tourism in a Changing World: Issues and Cases, London: Routledge.

Beeton, S. (2004). Rural tourism in Australia: has the gaze altered? Tracking rural images through film and tourism promotion. Progress in Tourism and Hospitality Research, 6(3), 125-135.

Bilgihan, A. Barreda, A., Okumus, F., \& Nusair, K. (2016). Consumer perception of knowledge-sharing in travelrelated Online Social Networks. Tourism Management, 52, 287-296.

Blain, C., Levy, S.E., \& Ritchie, J.R.B. (2005). Destination branding: Insights and practises from destination management organizations. Journal of Travel Research, 43, 328-338.

Boyd, D., \& Ellison, N., (2008). Social network sites: Definition, history, and scholarship. Journal of ComputerMediated Communication, 13, 210-230.

Borges, B. (2009). Marketing 2.0: Bridging the gap between seller and buyer through social media marketing. Tucson, AZ: Wheatmark.

Buhalis, D., \& Foerste, M. (2015). SoCoMo marketing for travel and tourism: Empowering co-creation of value Journal of Destination Marketing \& Management, 4(3), 151-161.

Buhalis, D., \& Law, R., (2008). Progress in tourism management: Twenty years on and 10 years after the internet: The state of e'Tourism research. Tourism Management, 29(4), 609-623.

Chung, J.Y., \& Buhalis, D., (2008). Information needs in online social networks. Information Technology and Tourism, 10(4), 267-282.

D’Aveni, R., (1994). Hypercompetition: managing the dynamics of strategic manoewving. New York: The Free Press.

DCG (2012) Certified Destination Management Executive (CDME) Programme.

Dijkmans, C., Kerkhof, P., \& Beukeboom, C.J. (2015). A stage to engage: Social media use and corporate reputation, Tourism Management, 47, 58-67.

Feng, R., Morrison, A.M., \& Ismail, J.A., (2003). East versus West: A comparison of online destination marketing in China and the USA. Journal of Vacation Marketing, 10(1), 43-56.

Fesenmaier, D., Gretzel, U., Hwang, Y. H., \& Wang, Y. (2003). The future of destination marketing: eCommerce in travel and tourism. International Journal of Tourism Science, 3(2), 191-200.

Fiore, A. M., Kim, J., \& Lee, H., (2005). Effect of image interactivity technology on consumer responses toward the online retailer. Journal of Interactive Marketing, 19(3), 38-53.

Ford, R.C., \& Peeper, W.C. (2007). The past as prologue: Predicting the future of the convention and visitor bureau industry. Tourism Management, 28(4), 1104-14.

Fotis, J., Buhalis, D., \& Rossides, N., (2011). Social media impact on holiday travel: The case of the Russian and the FSU markets, International Journal of Online Marketing, 1(4), 1-19. 
Frick, T. (2010). Return on Engagement: Content, Strategy, and Design Techniques for Digital Marketing. Burlington, MA: Focal Press.

Gartrell, R.B. (1992). Convention and visitor bureau: Current issues in management and marketing. Journal of Travel \& Tourism Marketing, 1(2), 71-78.

Gioia, D. A., Corley, K. G., \& Hamilton, A. G. (2013). Seeking qualitative rigor in inductive research: notes on the Gioia methodology. Organization Research Methods, 16(1), 15-31.

Greene, W.H. (2003) Econometric Analysis. Pearson Education.

Gretzel, U., (2006). Consumer generated content - trends and implications for branding. E-review of Tourism Research, 4(3), 9-11.

Gretzel, U., Yuan, Y., \& Fesenmaier, D., (2000). Preparing for the new economadvertising strategies and change in destination marketing organizations. Journal of Travel Research, 39, 149-156.

Hays, S., Page, S., \& Buhalis, D., (2013). Social media as a destination marketing tool: its use by national tourism organisations. Current Issues in Tourism, 16(3), 211-239.

Hsiao, C. (2003). Analysis with panel data. Cambridge University Press.

Jick, T. D. (1979). Mixing qualitative and quantitative methods: Triangulation in action. Administrative Science Quarterly, 24, 602-611.

Laws, E. (1997). Managing Packaged Tourism. London: Thomson Business Press.

Läesser, C. (2000). Implementing destination-structures: experiences with Swiss cases. In Manete, M., \& Cerato, M. (Eds). From Destination to Destination Marketing and Management. Venice: CISET, 111-126.

Leung, D., Law, R., van Hoof, H. \& Buhalis, D., (2013). Social media in tourism and hospitality: a literature review. Journal of Travel \& Tourism Marketing, 30, 3-22.

Luo, Q. \& Zhong, D. (2015). Using social network analysis to explain communication characteristics of travelrelated electronic word-of-mouth on social networking sites. Tourism Management, 46, 274-282.

Malhotra, N.K. (1996). Marketing Research: An Applied Orientation. 2nd Ed. Upper Saddle River, NJ: Prentice Hall.

Mariani, M.M., Giorgio, L. (2017). The 'Pink Night' festival revisited: Meta-events and the role of destination partnerships in staging event tourism, Annals of Tourism Research, 62(1), 89-109.

Mariani, M. M. Di Felice, M. \& Mura, M. (2016). Facebook as a Destination Marketing Tool: Evidence from Italian regional Destination Management Organizations. Tourism Management, 54, 321-343.

Mariani, M.M, Buhalis, D. Longhi C., \& Vitouladiti, O. (2014). Managing change in tourism destinations: Key issues and current trends, Journal of Destination Marketing \& Management, 2, 269-272.

Mariani, M.M., Baggio, R., Buhalis, D., \& Longhi, C. (2014b). Conclusion. In Mariani, M.M., Baggio, R., Buhalis, D., Longhi, C. (eds.), Tourism Management, Marketing and Development: the Importance of Networks and ICTs. New York: Palgrave, pp. 257-259

Mariani, M. M. Baggio, R. Buhalis \& Longhi, C. (2014a). Tourism Management, Marketing, and Development Volume I: The Importance of Networks and ICTs. New York: Palgrave-Macmillan. 
Mariani, M.M., \& Baggio R. (2012). Special Issue: Managing Tourism in a Changing World: Issues and Cases, Anatolia: An International Journal of Tourism and Hospitality Research, 23(1): pp. 1-3.

Marine-Roig, E. Anton Clavé, S. (2015). Tourism analytics with massive user-generated content: A case study of Barcelona, Journal of Destination Marketing \& Management, 4(3), 162-172

McClure, M. (2004). The Wonder Country: Making New Zealand Tourism. Auckland: Auckland University Press.

Morrison, A. (2013). Marketing and Managing Tourism Destinaitions. New York: Routledge.

Munar, A.M., \& Jacobsen, S.J.K. (2014). Motivations for sharing tourism experiences through social media. Tourism Management, 43, 46-54.

NZTPD. (1976). 75 Years of Tourism. Wellington: New Zealand Tourist \& Publicity Department.

Oviedo-García, A., Muñoz-Expósito, M., Castellanos-Verdugo, M. \& Sancho-Mejías, M. (2014). Metric proposal for customer engagement in Facebook. Journal of Research in Interactive Marketing, 8(4), 327-344

Oxford Economics (2014). The Return on Investment of Brand USA Marketing 2014 Fiscal Year Analysis, Available online at: http://www.thebrandusa.com/research-analytics/roi-study

Pike, S, \& Page, S. (2014). Destination Marketing Organizations and destination marketing: A narrative analysis of the literature. Tourism Management, 41, 202-227.

Pike, S. (2008). Destination Marketing. Burlington, MA: Butterworth-Heinemann.

Pine, J.B. \& Gilmore, J.H. (1998). Welcome to the Experience Economy. Harvard Business Review, July-August 1998, 97-105.

Porter, M. (1990). The competitive advantage of nations. Harvard Business Review, 68(2) (March-April 1990), $73-$ 93. Qualman, E. (2009). Socialnomics: How social media transforms the way we live and do business. Hoboken, NJ: John Wiley and Sons.

Qualman, E. (2009). Socialnomics: How social media transforms the way we live and do business. Hoboken, NJ: John Wiley and Sons.

Ritchie, B. J. R., Crouch, G. I. (2000). The Competitive Destination: A Sustainable Perspective. Tourism Management, 21(1): 1-7.

Shea, L., Enghagen, L., \& Khullar, A., (2004). Internet diffusion of an e-complaint: A content analysis of unsolicited responses. Journal of Travel \& Tourism Marketing, 17(2/3), 105-116

Schegg, R., Liebrich, A., Scaglione, M., \& Ahmad, S.F.S., (2008). An exploratory field study of web 2.0 in tourism. Information and Communication Technologies in Tourism, 5, 152-163.

Schetzina, C., (2010): Introduction to social media analytics. New York, NY: PhoCusWright.

Sigala, M., Christou, E., \& Gretzel, U. (2012). Social Media in Travel, Tourism and Hospitality: Theory, Practice and Cases. Ashgate Publishing, Ltd.

SocialBakers (2015). Social Bakers Analytics. User Guide. Available online at: http://analytics.socialbakers.com/template/classic/media/SocialbakersAnalyticsGuide.pdf

Stankov, U., Lazic, L., \& Dragicevic, V., (2010). The extent of use of basic Facebook user-generated content by the national tourism organizations in Europe, European Journal of Tourism Research, 3(2), 105-113. 
Stepchenkova, S., Mills, J. E., \& Jiang, H., (2007). Virtual travel communities: Self-reported experiences and satisfaction. In M. Sigala, L. Mich, \& J. Murphy (Eds.), Information and communication technologies in tourism (New York: Springer Wien), 163-174.

UNWTO (2015). Tourism Highlights, 2015 Edition. Madrid: UNWTO.

Verhoef, P.C., Kooge, E., Walk, N., (2016). Creating V alue with Big Data Analytics: Making Smarter Marketing Decisions. Routledge: London.

Walton, J.K. (1983). The English Seaside Resort - A Social History 1750-1914. Leicester: Leicester University press.

Wang, Y., Yu, Q., \& Fesenmaier, R..D., (2002). Defining the virtual tourist community: Implications for tourism marketing. Tourism Management, 23(4), 407-417.

Wang, Y., \& Fesenmaier, D. R., (2004). Towards understanding members' general participation in and active contribution to an online travel community. Tourism Management, 25(6), 709-722.

Ward, S. (1995). Selling Places: The Marketing and Promotion of Towns and Cities. E\&F Spon: London

Wenger, A., (2008). Analysis of travel bloggers' characteristics and their communication about Austria as a tourism destination. Journal of V acation Marketing, 14(2), 169-176.

White, N., \& White, P., (2007). Home and away: Tourists in a connected world. Annals of Tourism Research, 34(1), 88-104.

Xiang, Z., \& Gretzel, U., (2010). Role of social media in online travel information search. Tourism Management, 31, 179-188.

Vilnai-Yavetz, I. \& Sigal T. (2015). A Picture Is Worth a Thousand Words: Segmenting Consumers by Facebook Profile Images, Journal of Interactive Marketing, 32, 53-69.

Zhou, L. (2014). Online rural destination images: Tourism and rurality. Journal of Destination Marketing \& Management, 3(4): 227-240. 
Figure 1. Type of posts by the selected NTOs (broken down by content), 2013-2015.

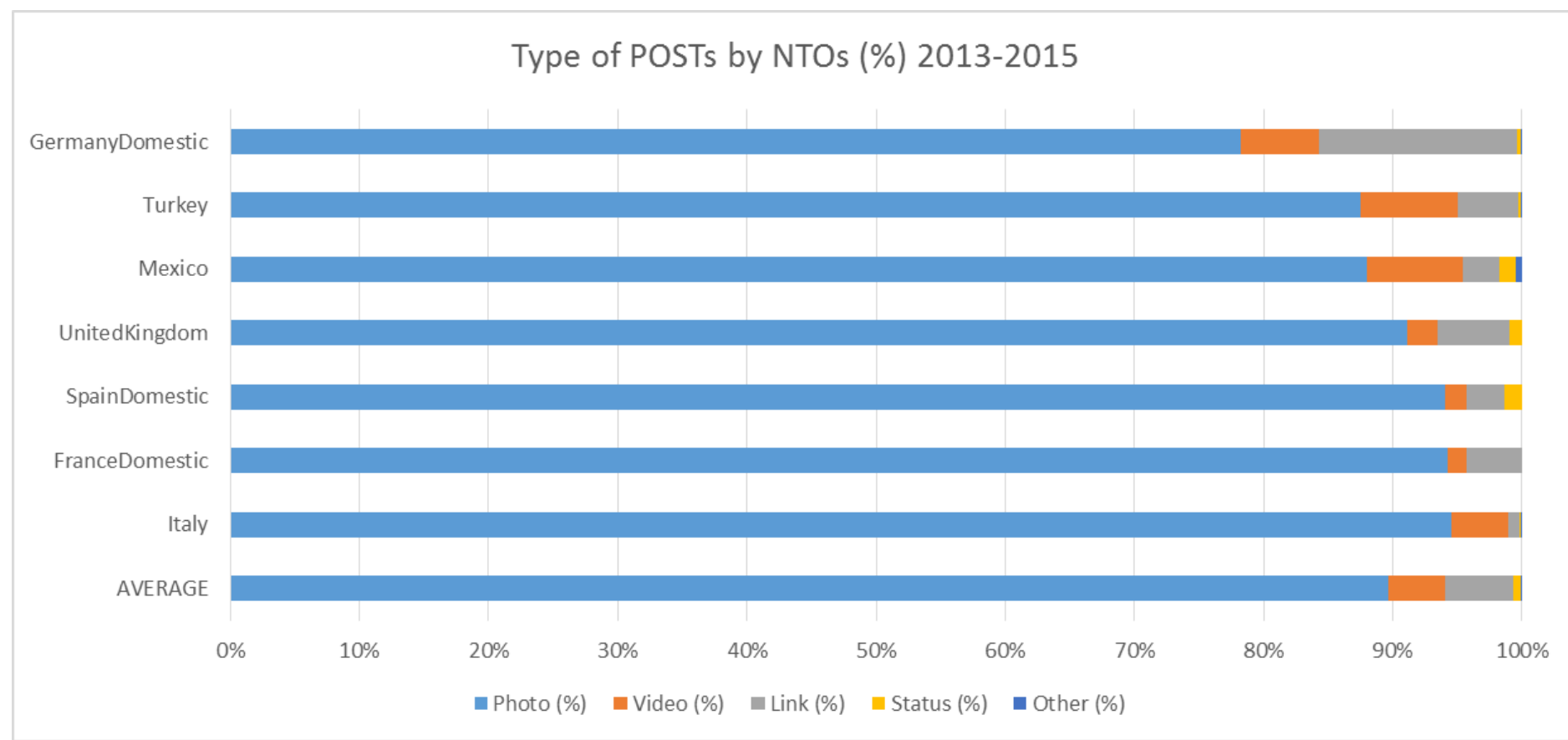


Figure 2. Number of "Likes", "Shares" and "Comments" by the selected NTOs and their users, 2013-2015.

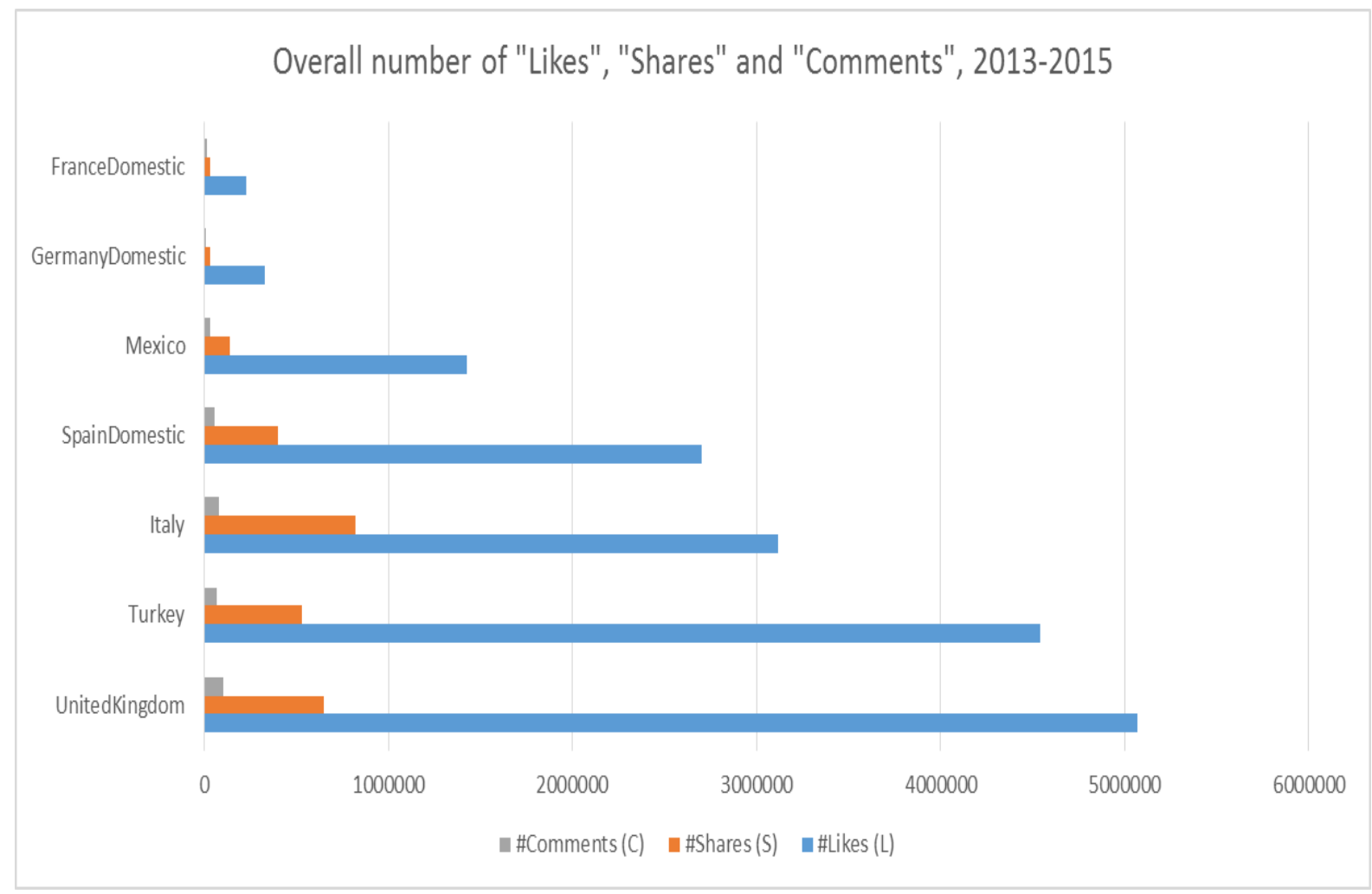


Figure 3. Number of Active Users (i.e., users posting at least one comment) over the period 2013-2015.

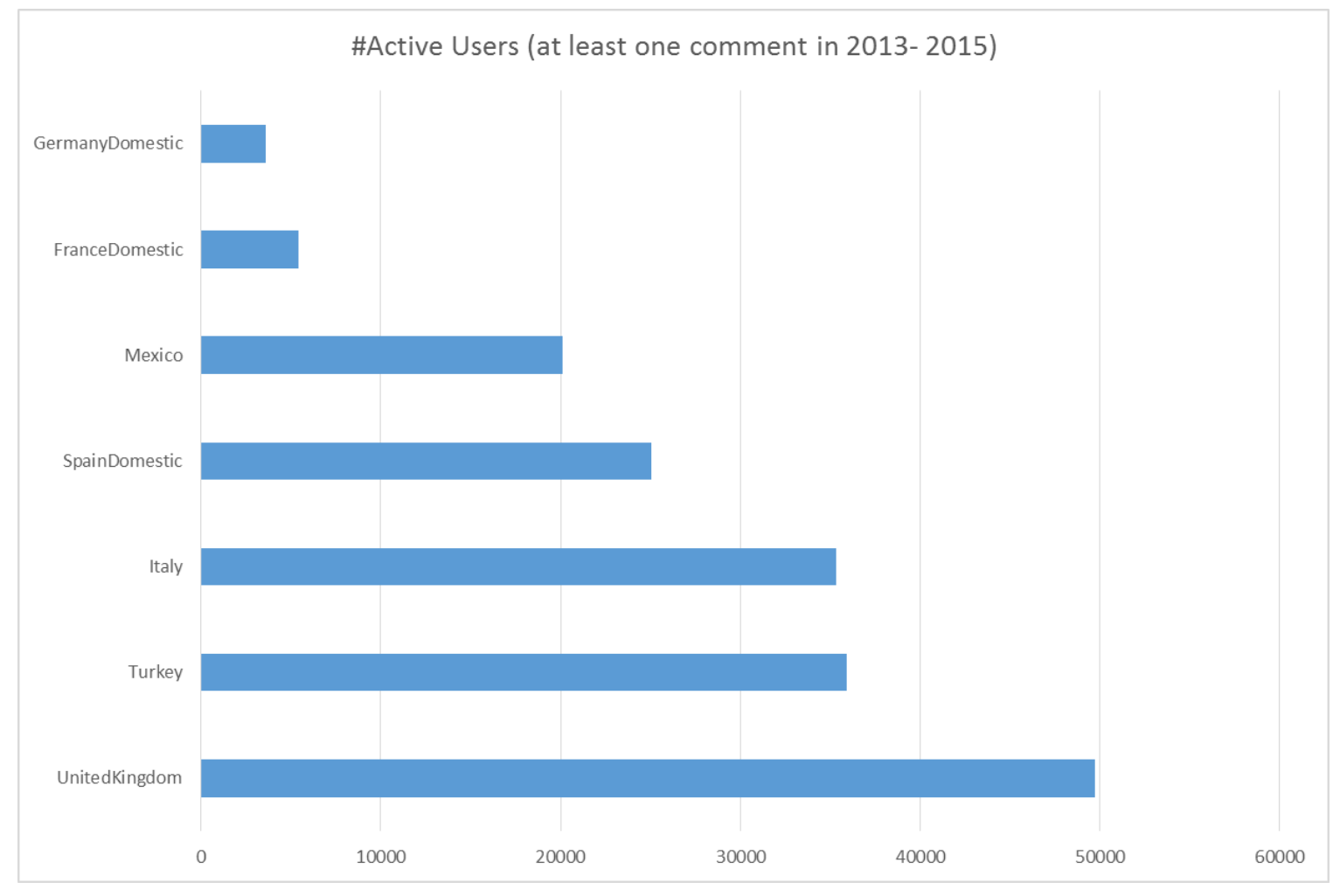


Figure 4. Distribution of the number of "Comments" by active users, 2013-2015.

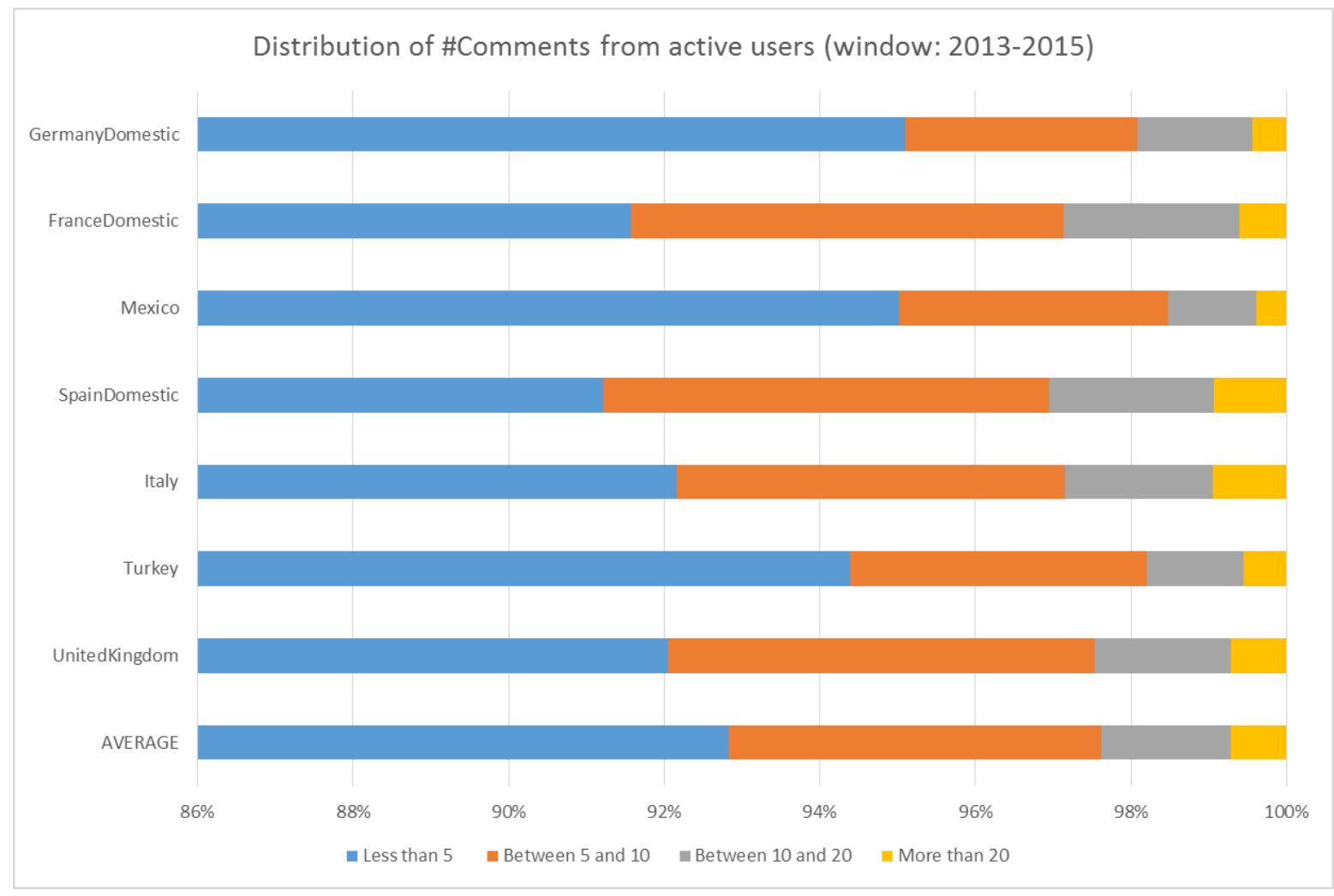


Figure 5. Generic and brand monthly engagement metrics for the sampled NTOs, 2013-2015.

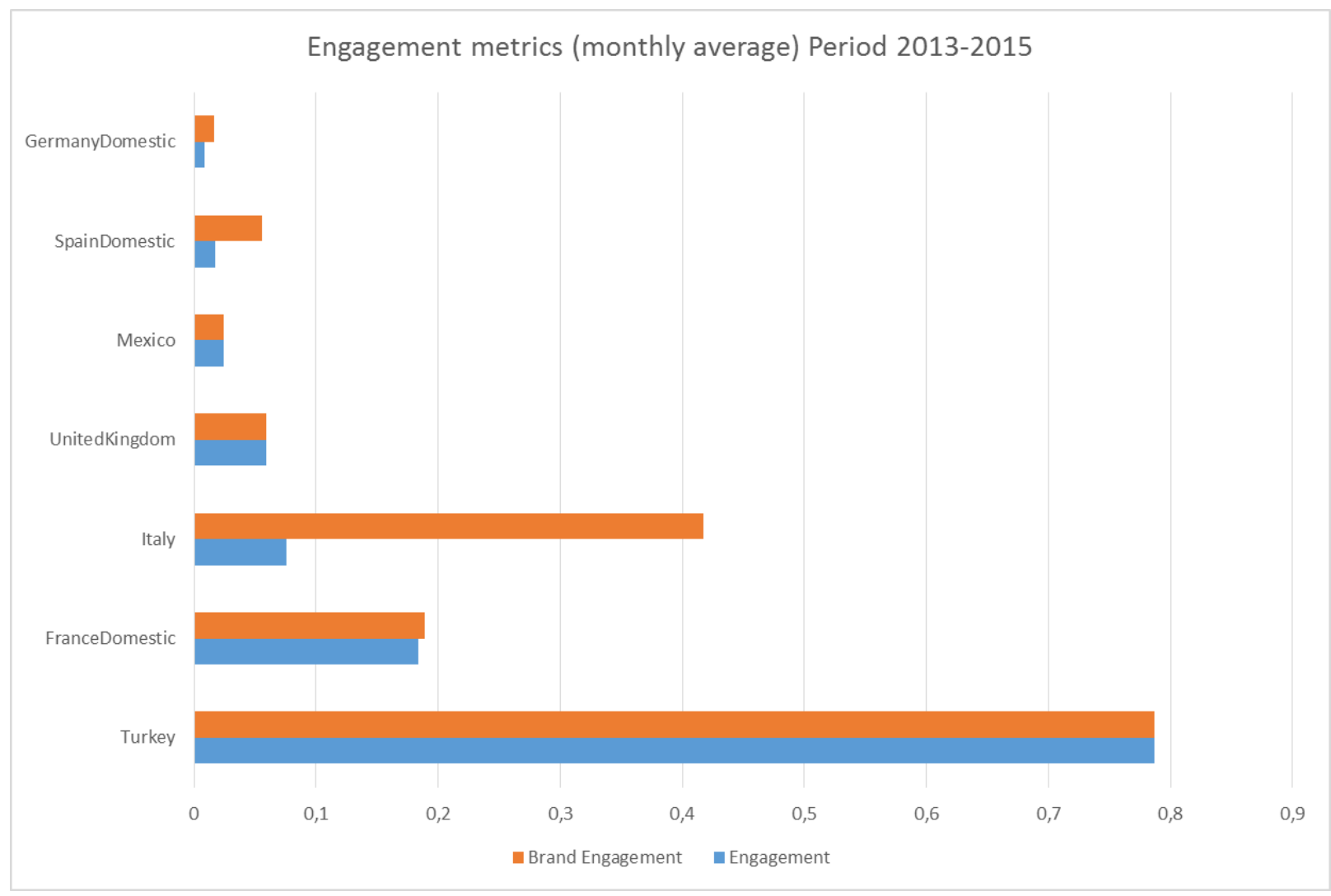


Figure 6. Generic Engagement for User's Activity (monthly average per post), 2013-2015.

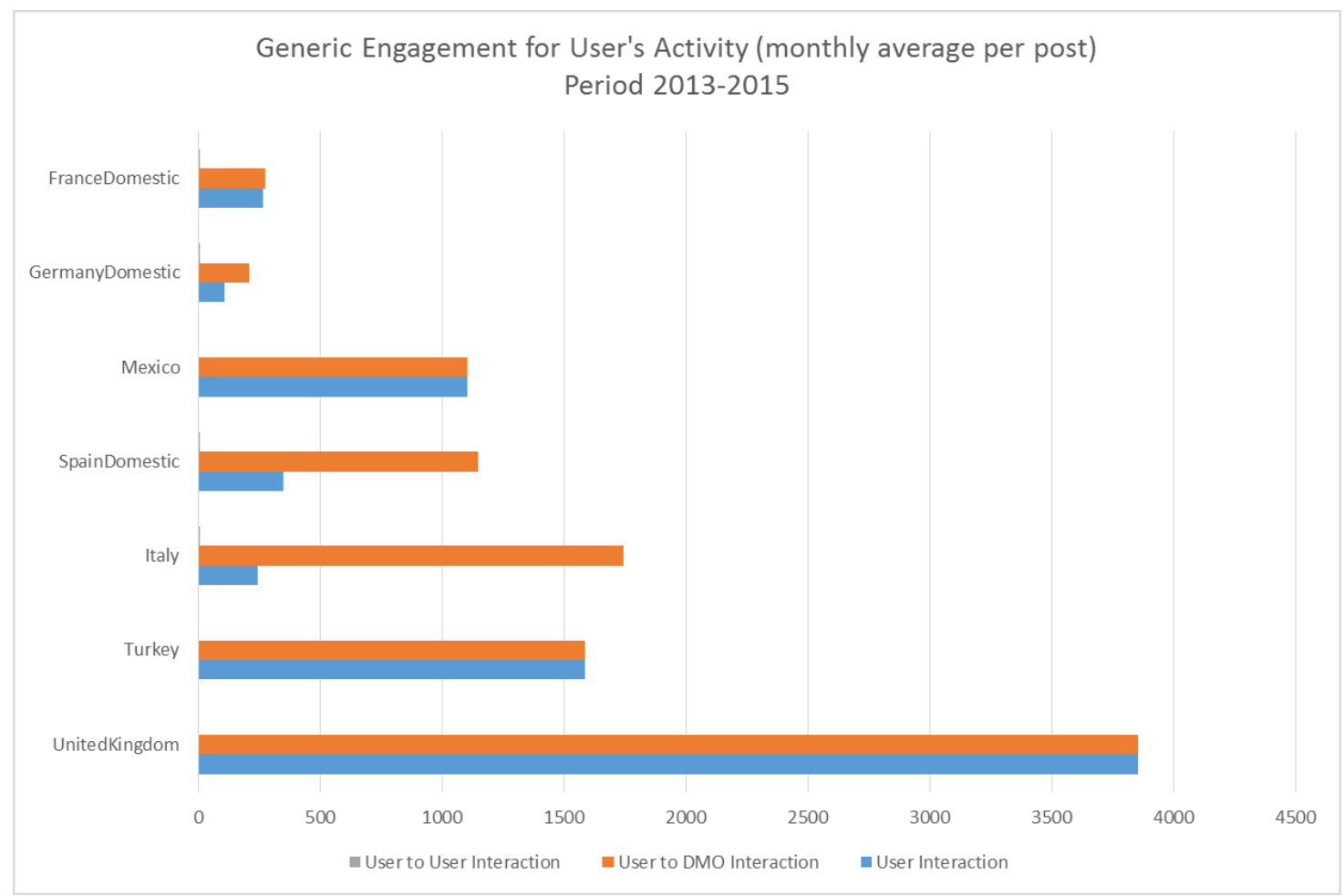


Figure 7. Non-normalized Generic Engagement for User's Activity, (monthly average) in 2013-2015

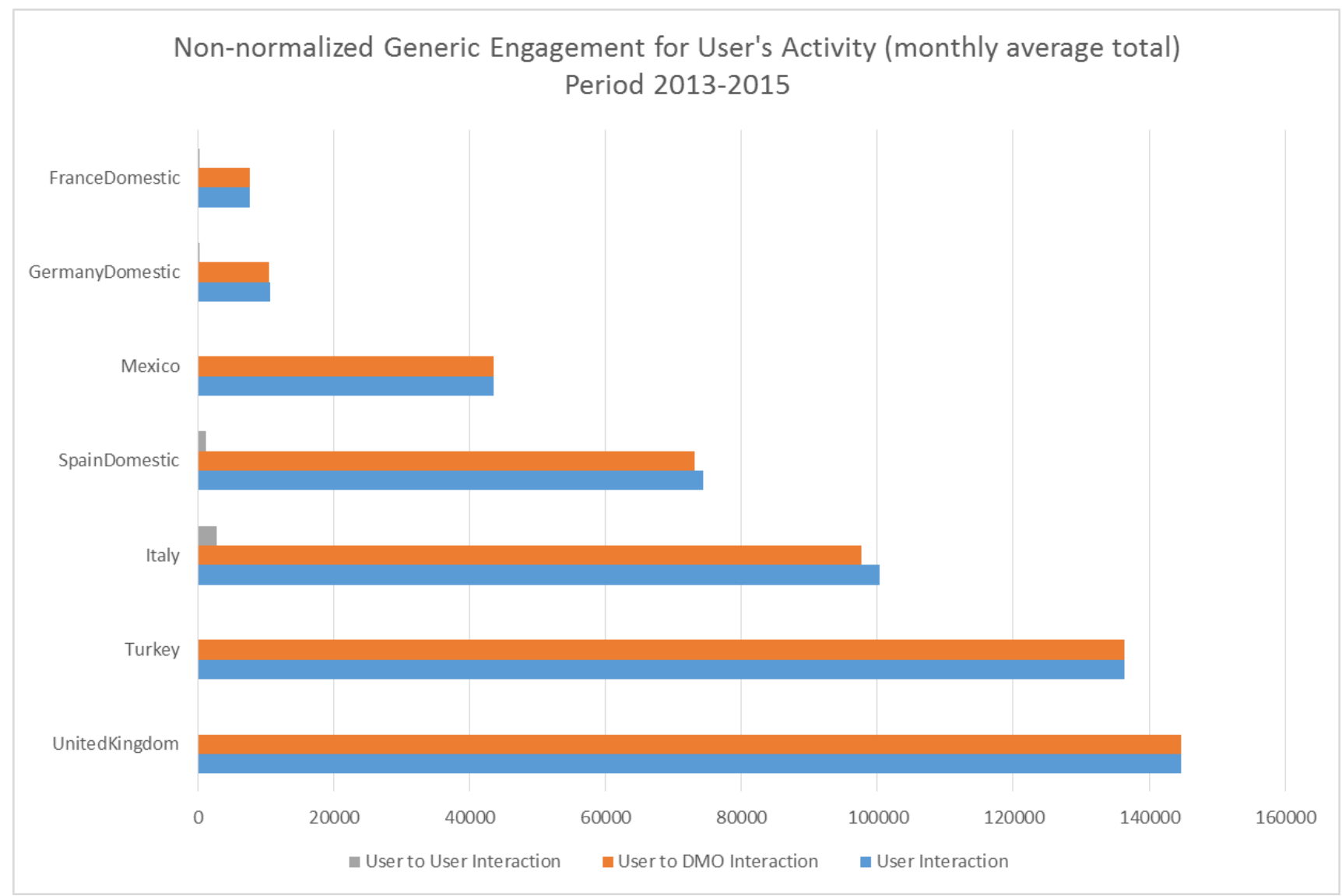


Figure 8. Average Generic Engagement for Users' Activity as a function of the type of post, 2013-2015

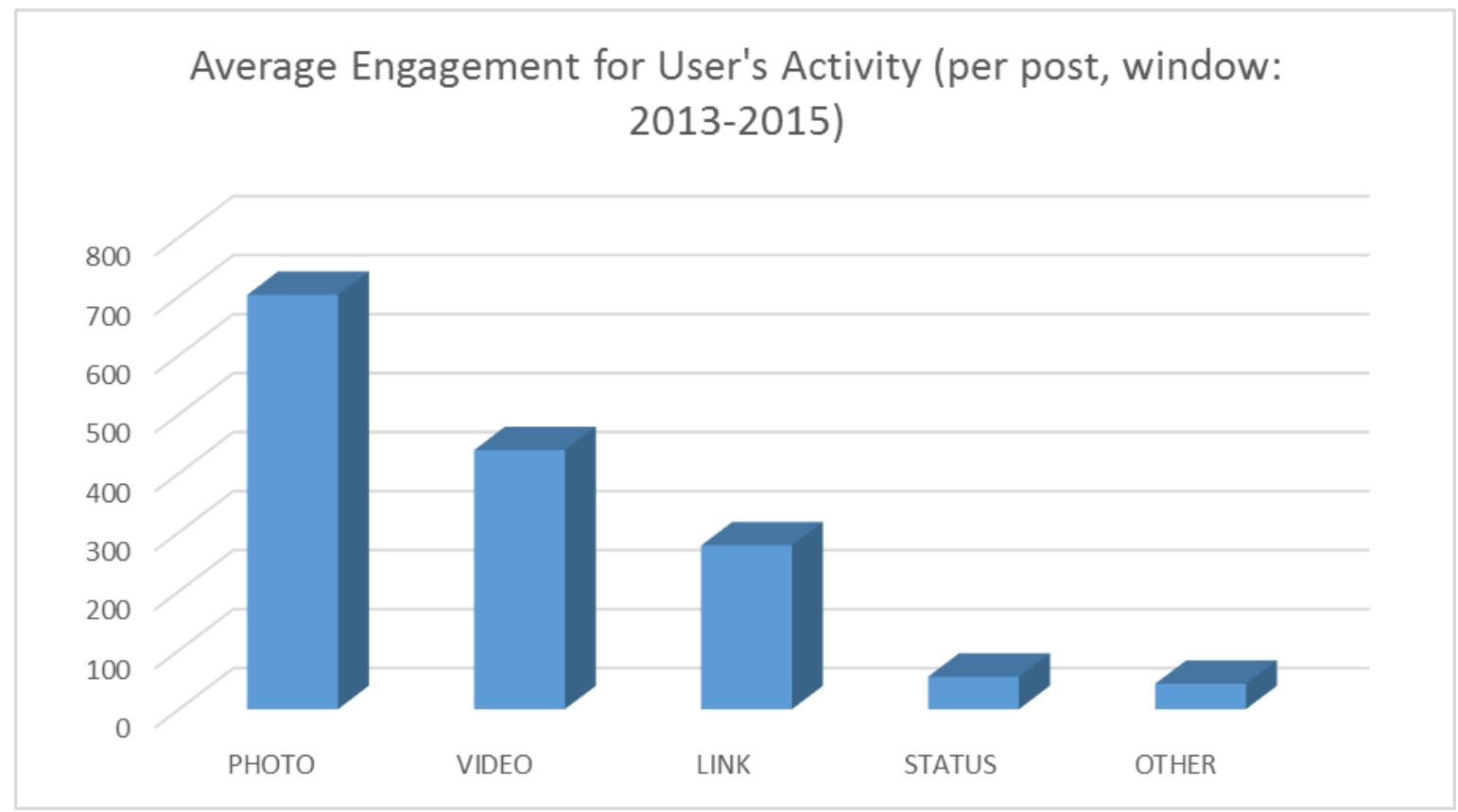


Figure 9. Distribution of posts by length for NTOs in 2013-2015

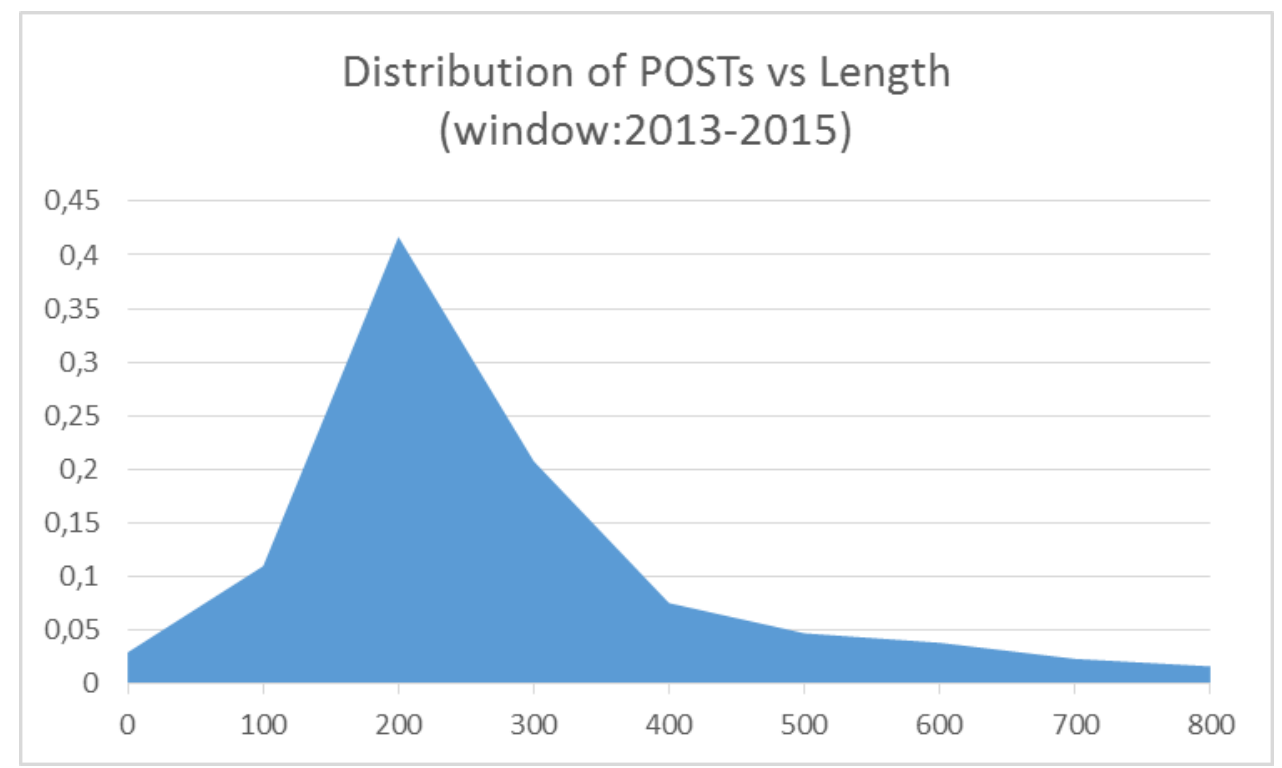


Figure 10. Average Generic Engagement for Users' activity as a function of the length of posts, 2013-2015

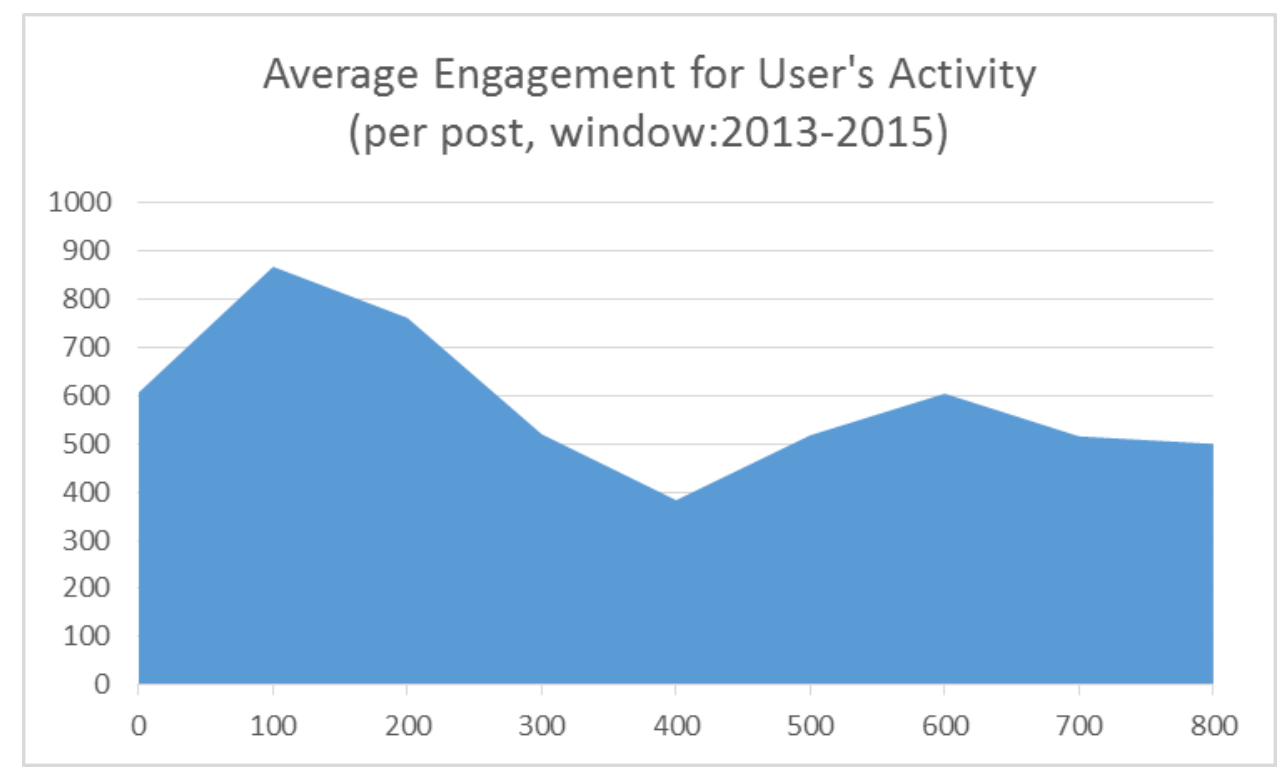


Figure 11. Distribution of posts according to the NTOs posting hour in 2013-2015

\section{Distribution of POSTs vs NTOs Posting Hour}

(window: 2013-2015)

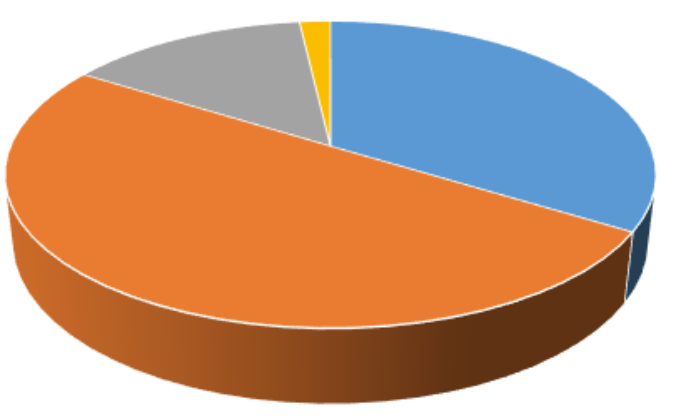

- Morning (6am-12am) - Afternoon (12am-6pm)

- Evening (6pm-12pm) - Night (12pm-6am) 
Figure 12. Average Generic engagement for Users' Activity as a function of the NTO posting hour in 2013-2015

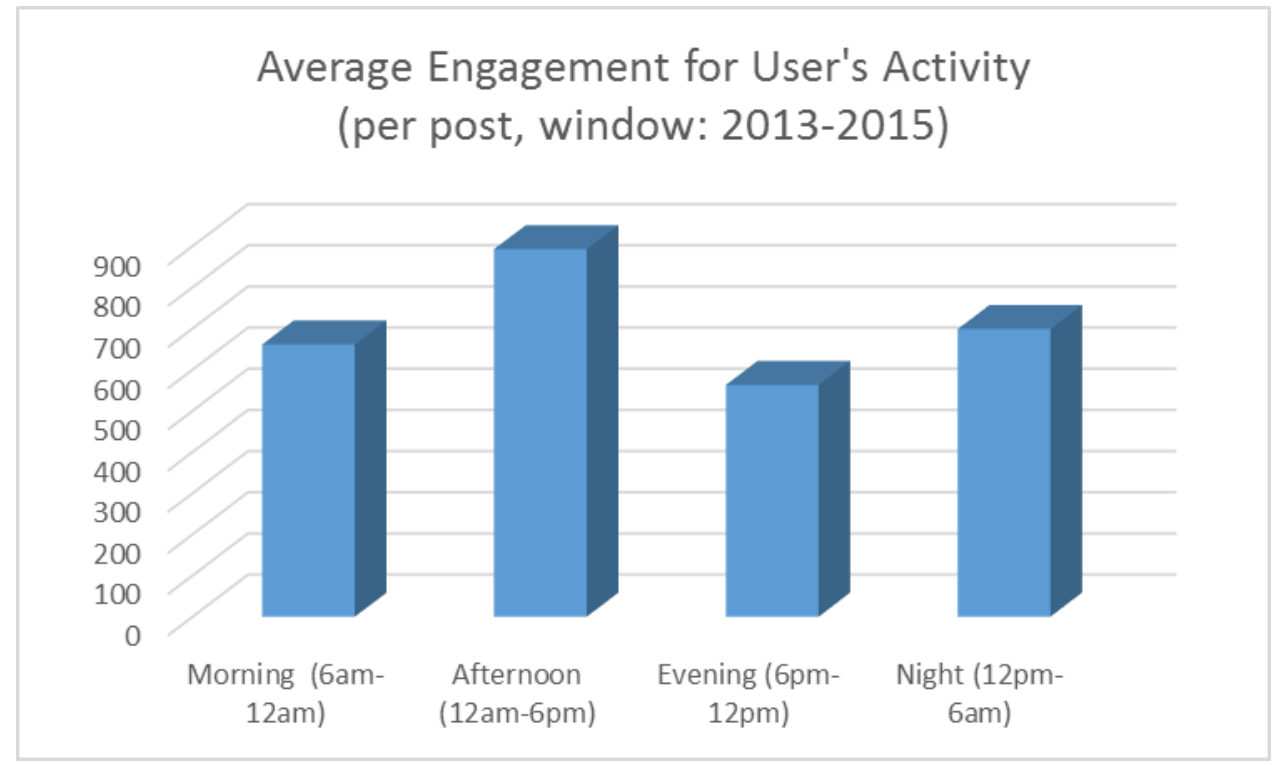


Figure 13. Average Generic Engagement for Users' Activity as a function of the NTO posting day of the week, 2013-2015

Average Engagement for User's Activity vs Day of the Week (per post, window:2013-2015)

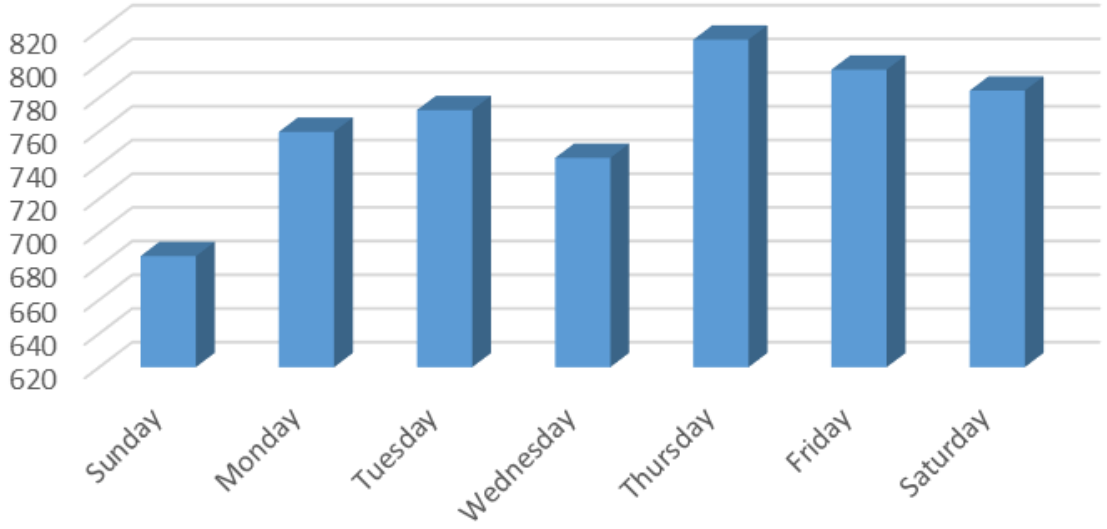


Figure 14. Distribution of posts according to the NTO daily posting frequency, 2013-2015

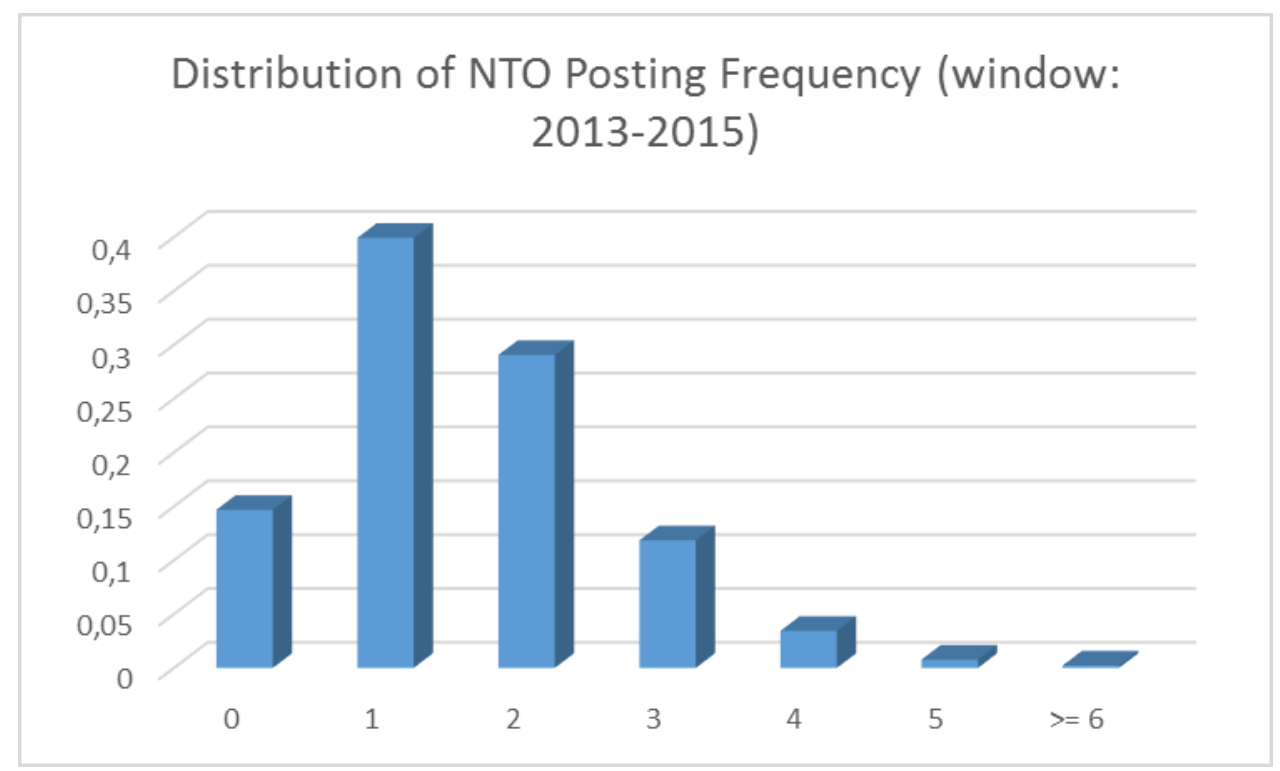


Figure 15. Average Generic Engagement per Users' Activity as a function of the NTO daily posting frequency, 2013-2015

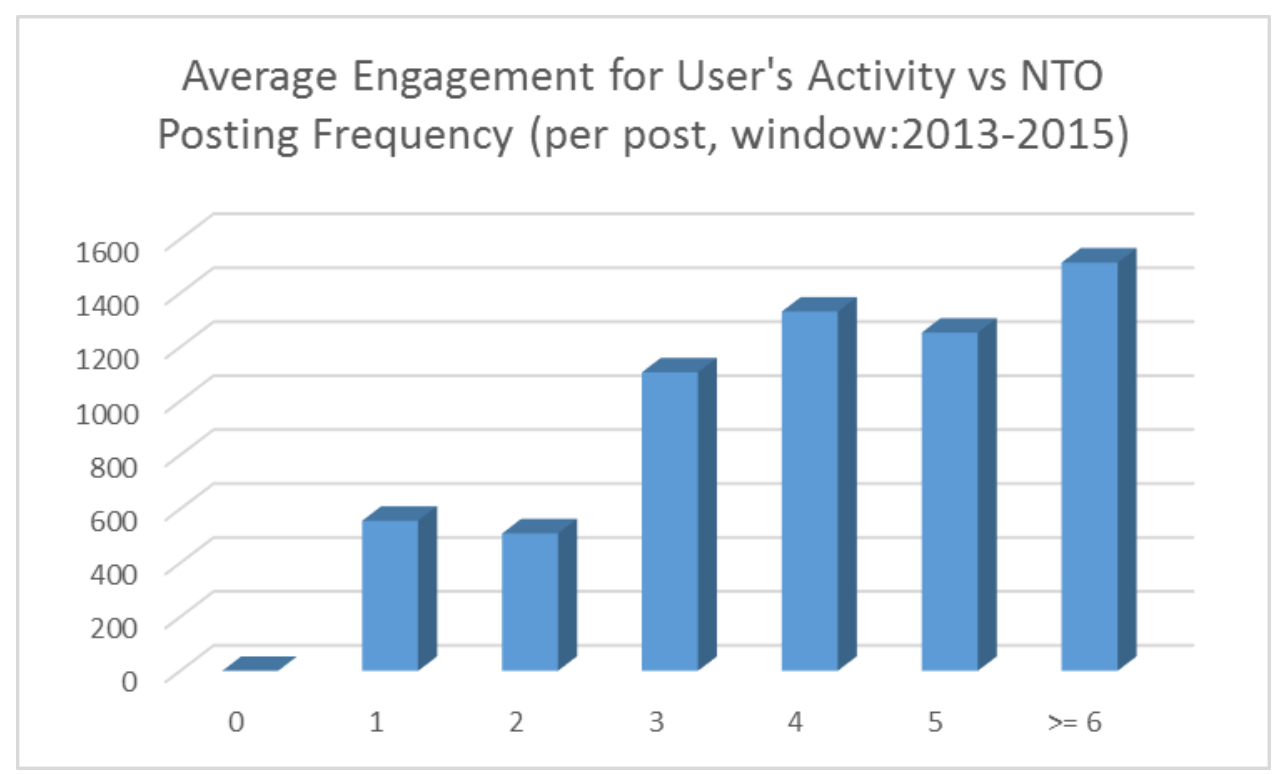


Figure 16. Engaging the users through professional edited visual content, Turkey Facebook page, 17 July 2014

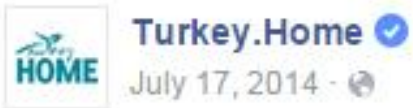

Don't miss \#swimming with ancient ruins in a natural pool, filled with mineral-rich hot springs, when in \#Pamukkale

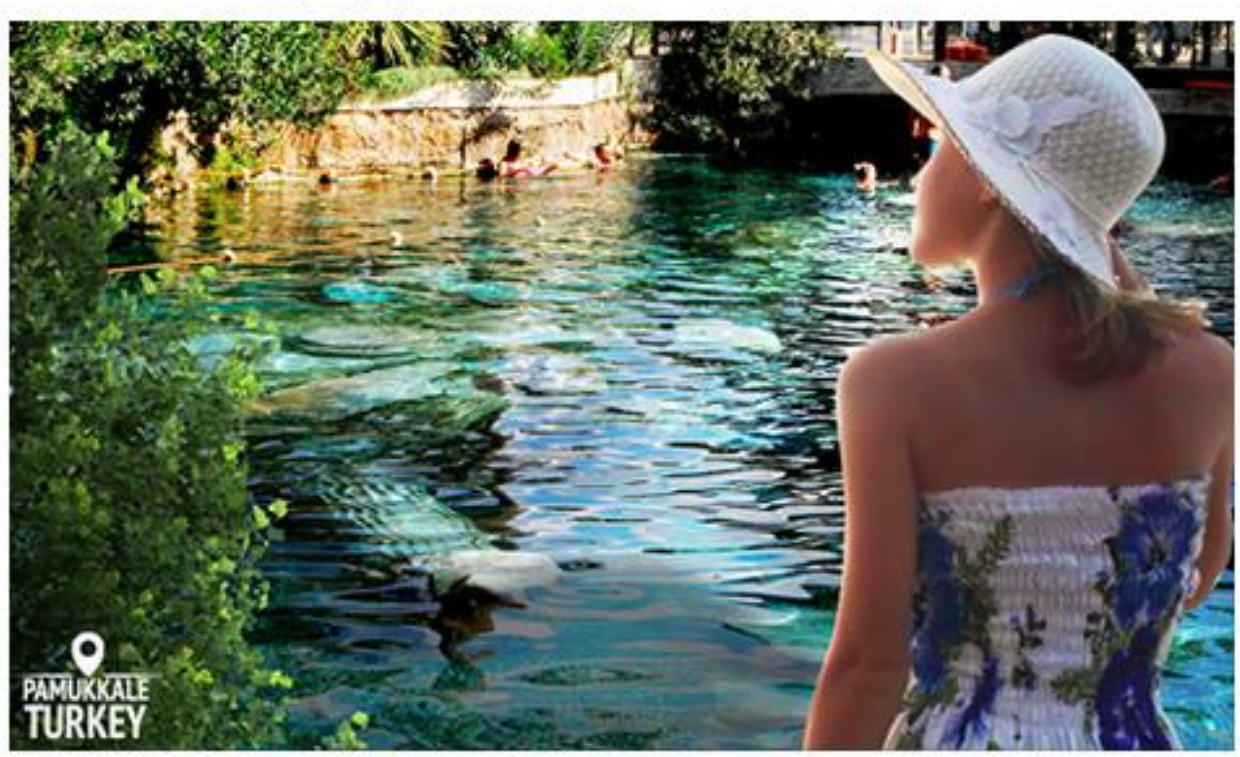

il Like $\quad$ Comment $\Rightarrow$ Share

81,669 people like this.

1,515 shares

View previous comments 
Figure 17. Creating compelling content for visitors and residents through the storytelling of a destination, Turkey NTO Facebook page, 10 November 2014 


\section{Turkey. Home $\odot$}

HOME November 10,2014 - a

What does it mean to residents of Istanbul to live in a city of two continents?

Just another day in paradise! In Istanbul two continents are just a routine part of the magic of the city. Whether its relaxation, commutes, jogs, swims or even wedding celebrations, people in Istanbul live their lives straddling Europe and Asia! \#Discover \#Turkey \#HomeOf \#TwoContinents \#Istanbul

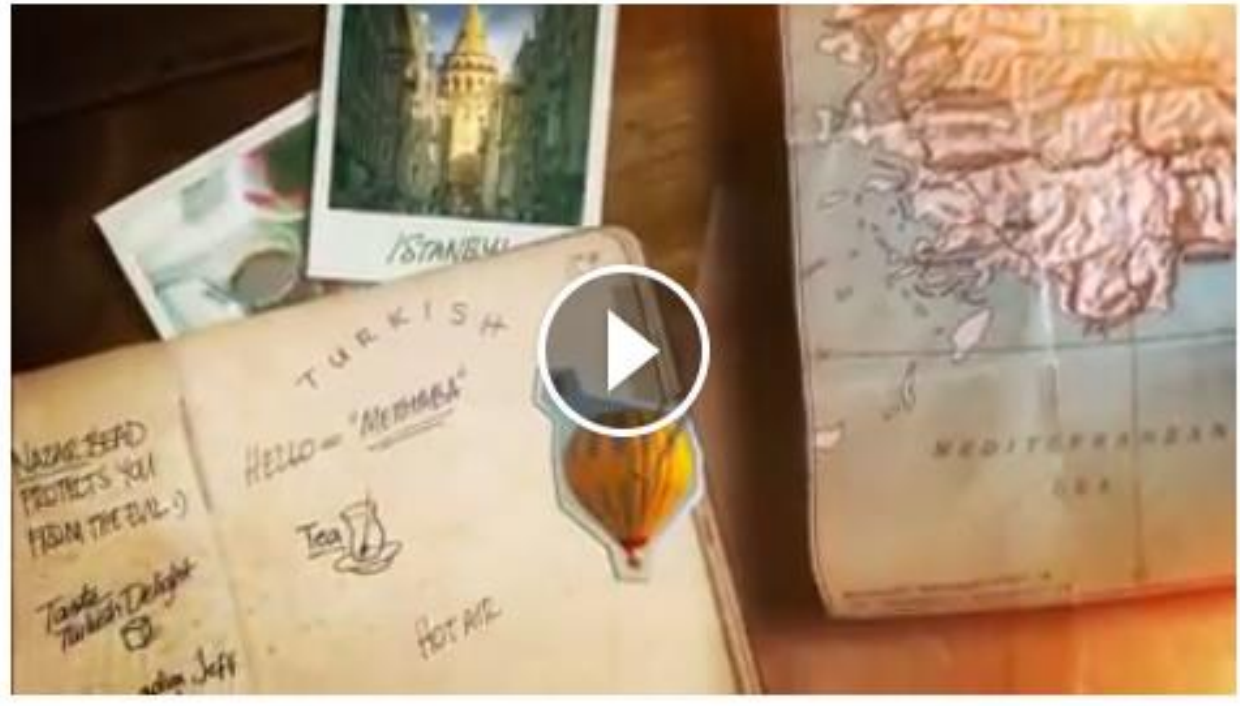

I Like Comment $\Rightarrow$ Share

5,743 people like this.

Most Recent *

11,777 shares

View previous comments

45 of 394 
Figure 18. Engaging the users through frequent compelling games,

UK Facebook page, 24 June 2014

GREAT Love GREAT Britain $>$ with Mario Gelini and 6 others

DINS June 24,2014 - (2)

It's \#BritQuestions Tuesday! Tell us 1 word that describes Great Britain for you. We'll compile all your words and share something special with you next Tuesday!

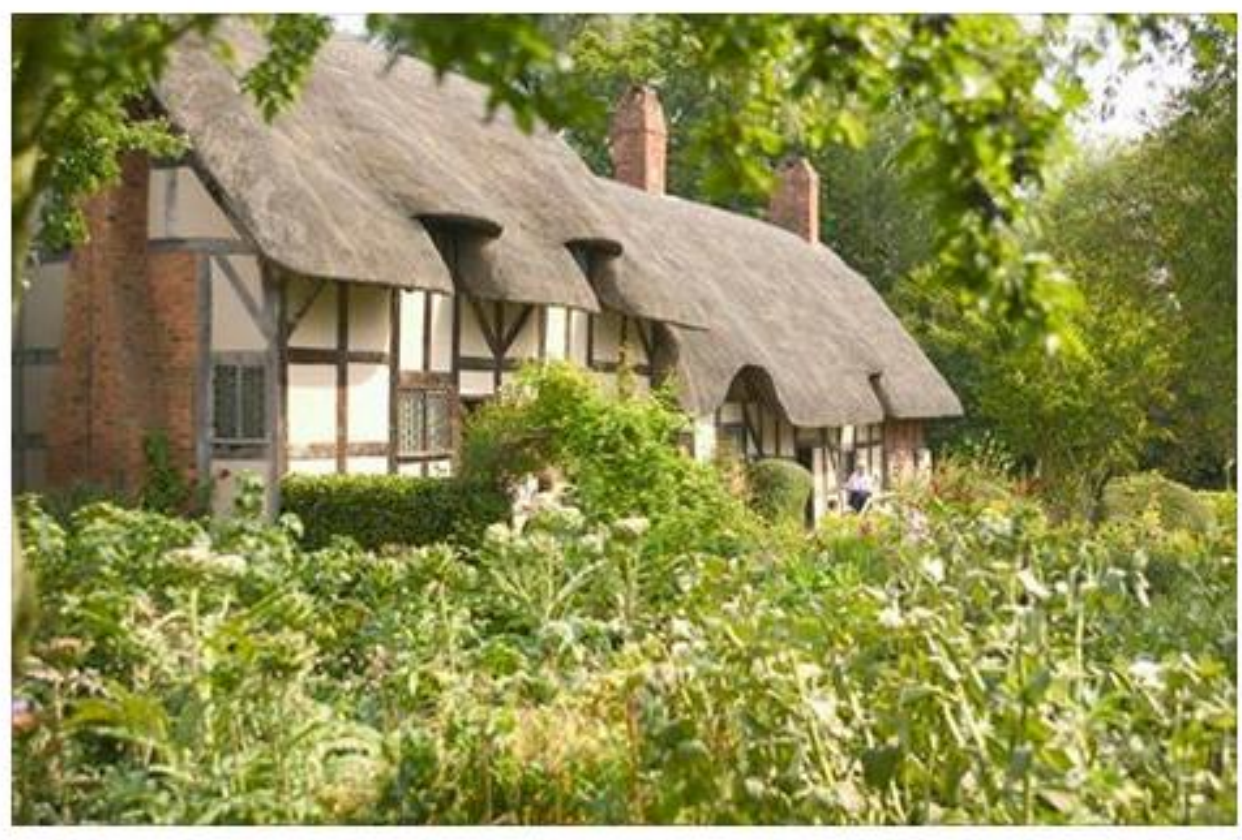

II Like Comment $\Rightarrow$ Share

11,590 people like this.

Most Relevant

1,252 shares 
Figure 19. Engaging the users through unique views and engaging texts/questions,

UK Facebook page, 7 March 2014

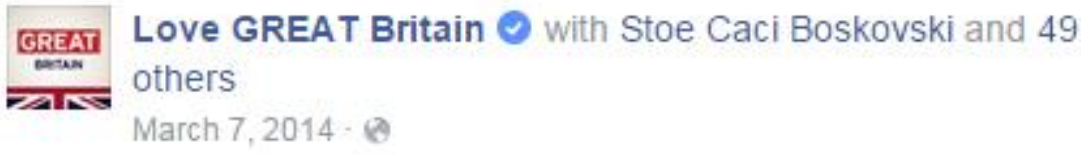

Like pubs? Like flowers? Check this pub out - the fabulous Churchill Arms in London! See more pubs in the UK: http://bit.ly/1avMs2p (Photo: Ben Cawthra/REX)

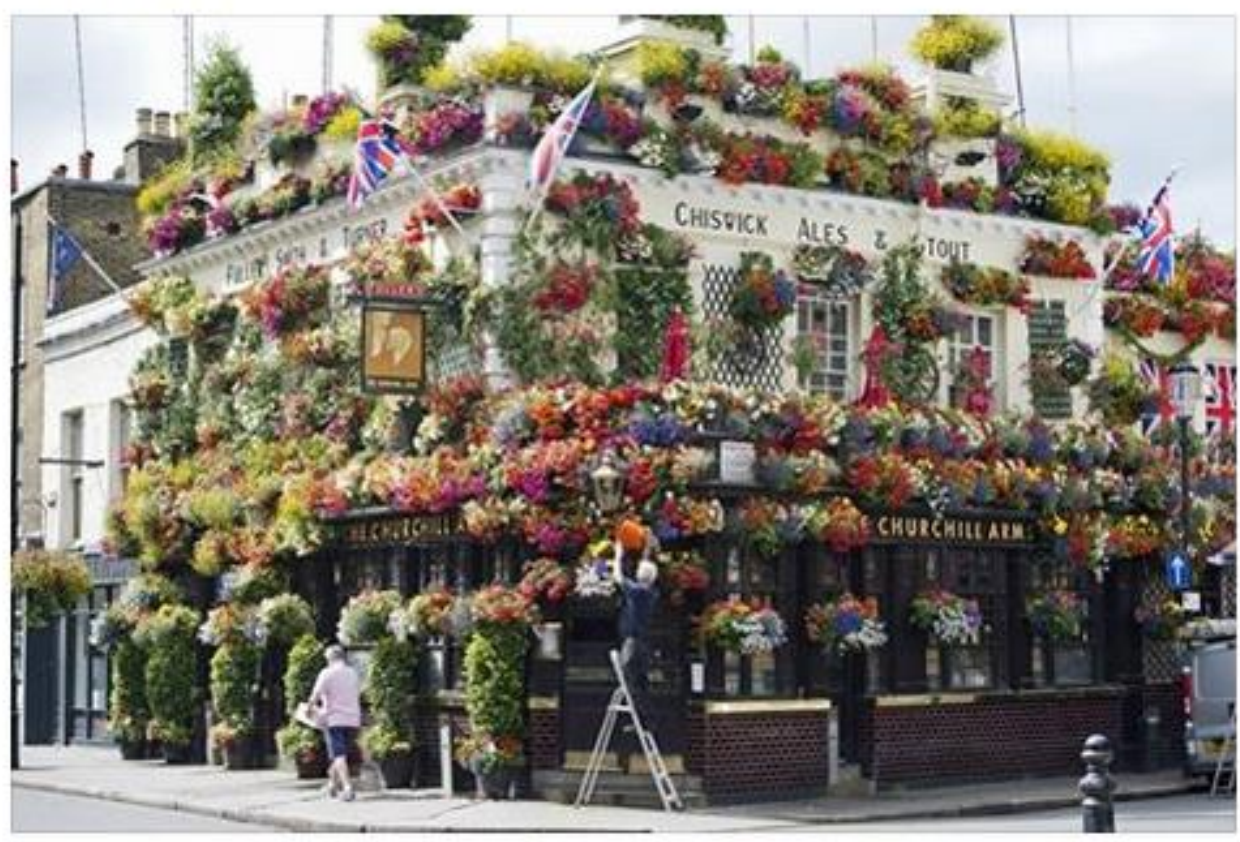
I耍 Like
Comment
$\Rightarrow$ Share

21,725 people like this.

Most Relevant*

8,825 shares 
Figure 20. Engaging the users through celebration of landmark events, Italy NTO Facebook page, 17 October 2014

\footnotetext{
Italia.it with Awest Excentriek II and 22 others

- October 17,2014-e
}

Capitale europea della cultura $2019 /$ European Capital of Culture 2019 Facciamo i nostri più sentiti complimenti a \#Matera (Basilicata)! Questo splendido sito UNESCO è stato appena nominato Capitale Europea della Cultura 2019! www matera-basilicata2019.it

Clicca "Mi Piace" sulla pagina Facebook di Comitato Matera 2019

Segui Matera2019 su Twitter https://twitter.com/Matera2019

We offer our warmest congratulations to Matera (Basilicata)!

This stunning UNESCO World Heritage Site has just been named

European Capital of Culture 2019! http://www matera-basilicata2019.it/en/ Head to the Facebook page of \#Matera2019: http://bit.ly/Matera2019Facebook

Follow Matera2019 on Twitter: https://twitter.com/Matera2019

\#ECOC2019 \#EuropeanCapitalOfCulture2019 EUROPE (visiteurope.com) \#llikeltaly \#Italia \#Italy

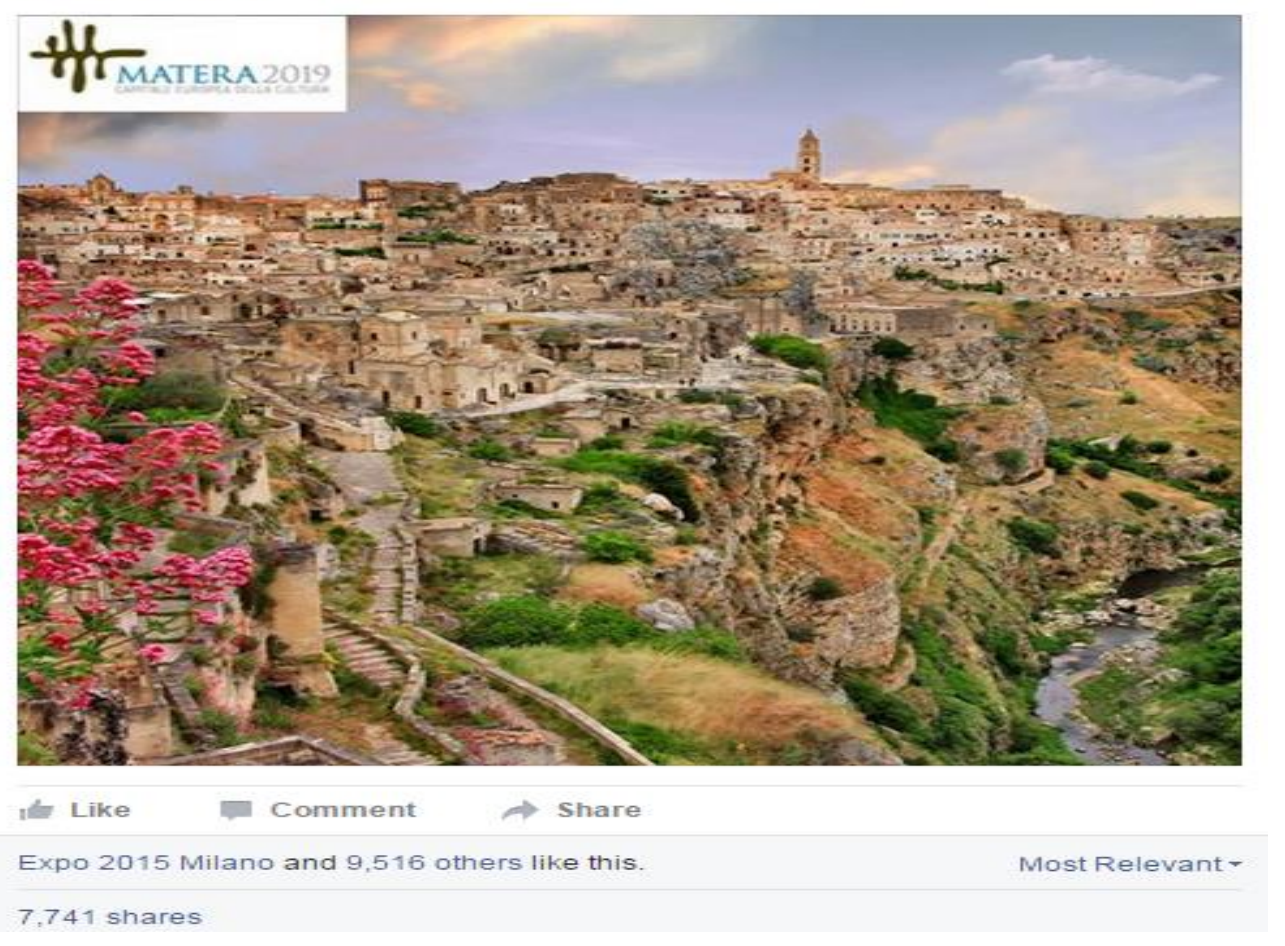


Table 1. List of measures used for the analysis of contents

- Number of overall posts (Total Posts), broken down into posts by the DMO (Posts_DMO) vs. posts by users (Posts_Users) (adapted from Hays et al., 2013)

- Type of posts by the DMO (Photo, Video, Link to a website, Status, Other ${ }^{1}$ ) (adapted from Hays et al., 2013)

- Overall number of likes for the page (Likes), with a break-down of the Number of likes by users (Likes_Users) [we collected this data for each post and then aggregated them] (adapted from Hays et al., 2013)

- Number of shares for the page (Shares), with a break-down of the Number of shares by users (Shares_Users) [we collected this data for each post and then aggregated them] (adapted from Hays et al., 2013)

- Number of comments for the page (Comments), with a break-down of the Number of comments by users (Comments_Users) [we collected these data for each post and then aggregated them] (adapted from Hays et al., 2013)

- Type of posts by the user (Photo, Video, Link to a website, Status, Other) (adapted from Mariani et al., 2016)

- Number of likes for content posted by users (Likes_Users2Users) (adapted from Mariani et al., 2016)

- Number of shares for content posted by users (Shares_Users2Users) (adapted from Mariani et al., 2016)

- Number of comments for content posted by users (Comments_Users2Users) (adapted from Mariani et al., 2016)

- Number of fans at the beginning of the year/month (Total Fans Beginning of Year; Total Fans Beginning of Month) (adapted from Mariani et al., 2016)

- Number of fans at the end of the year/month (Total Fans End of Year; Total Fans End of Month) (adapted from Mariani et al., 2016)

1 "Other" could refer to mere audio content 
Table 2. List of measures used to assess monthly engagement

1. Generic Engagement, calculated on a monthly basis according to the following formula:

$$
\frac{(\text { Likes }+ \text { Comments }+ \text { Shares })}{(\text { Total_Posts Total_Fans }(\text { end_of_the_month }))} 100
$$

2. Brand Engagement, calculated on a monthly basis according to the following formula:

$$
\frac{(\text { Likes_Users }+ \text { Comments_Users +Shares_Users })}{(\text { Posts_DMO Total_Fans }(\text { end_of_the_month }))} 100
$$

3. User Engagement, calculated on a monthly basis according to the following formula:

$$
\frac{(\text { Likes_Users2Users +Comments_Users2Users + Shares_Users2Users })}{(\text { Posts_Users Total_Fans }(\text { end_of_the_month }))} 100
$$


Table 3. List of additional measures of users' monthly engagement

1. Generic Engagement, for users' activity, calculated on a monthly basis according to the following formula:

$$
\frac{(\text { Likes }+ \text { Comments }+ \text { Shares })}{(\text { Total_Posts })} 100
$$

2. Brand Engagement for users' activity, calculated on a monthly basis according to the following formula:

$$
\frac{(\text { Likes_Users+Comments_Users+Shares_Users })}{(\text { Posts_DMO })} 100
$$

3. User Engagement for users' activity, calculated on a monthly basis according to the following formula:

$$
\frac{(\text { Likes_Users2Users+Comments_Users2Users+Shares_Users2Users })}{(\text { Posts_Users })} 100
$$


Table 4 Overall population of posts for the selected seven NTOs accounts, 2013-2015

Country
Italy
Spain (Domestic)
Germany (Domestic)
Turkey
Mexico
United Kingdom
France (Domestic)

Overall Total

Total Posts
9,735
5,006
2,109
1,210
965
913
643

20,221

$\begin{array}{rr}\text { Total Posts } & \text { \%Posts NTO on Total } \\ \text { NTO } & \text { Posts } \\ 1,439 & 14.8 \% \\ 1,503 & 30.0 \% \\ 942 & 44.7 \% \\ 1,210 & 100.0 \% \\ 965 & 100.0 \% \\ 913 & 100.0 \% \\ 629 & 97.8 \%\end{array}$

7,601

$37.6 \%$ 
Table 5.a Number of "Likes", "Shares" and "Comments" by the selected 15 NTOs and their users in 2013-

2015.

\begin{tabular}{|c|c|c|c|c|c|c|c|}
\hline \multirow[b]{2}{*}{ Country } & \multicolumn{3}{|c|}{ Performed by NTOs and users } & \multicolumn{4}{|c|}{ Performed by users only } \\
\hline & \#Likes (L) & \#Shares (S) & \#Comments (C) & \#Shares (SU) & $\% s u / s$ & \#Comments (CU) & $\% \mathrm{CU} / \mathrm{C}$ \\
\hline UnitedKingdom & 5070838 & 647937 & 105654 & 647937 & $100,00 \%$ & 105335 & $99,70 \%$ \\
\hline Turkey & 4541343 & 533333 & 67571 & 533333 & $100,00 \%$ & 67571 & $100,00 \%$ \\
\hline Italy & 3114870 & 820588 & 79099 & 820588 & $100,00 \%$ & 78621 & $99,40 \%$ \\
\hline SpainDomestic & 2702193 & 402459 & 58147 & 402459 & $100,00 \%$ & 57927 & $99,62 \%$ \\
\hline Mexico & 1426346 & 141512 & 34944 & 141512 & $100,00 \%$ & 34868 & $99,78 \%$ \\
\hline GermanyInternational & 364402 & 18650 & 27650 & 18650 & $100,00 \%$ & 26948 & $97,46 \%$ \\
\hline GermanyDomestic & 329066 & 33492 & 7029 & 33492 & $100,00 \%$ & 6178 & $87,89 \%$ \\
\hline FranceDomestic & 228942 & 30241 & 11917 & 30241 & $100,00 \%$ & 11761 & $98,69 \%$ \\
\hline UnitedStatesInternational & 195708 & 21110 & 5598 & 21110 & $100,00 \%$ & 5451 & $97,37 \%$ \\
\hline SpainInternational & 164551 & 22185 & 10235 & 22185 & $100,00 \%$ & 10165 & $99,32 \%$ \\
\hline UnitedStatesDomestic & 88200 & 11796 & 2135 & 11796 & $100,00 \%$ & 2087 & $97,75 \%$ \\
\hline Francelnternational & 36226 & 5292 & 2545 & 5292 & $100,00 \%$ & 2457 & $96,54 \%$ \\
\hline Chinalnternational & 27883 & 1389 & 332 & 1389 & $100,00 \%$ & 330 & $99,40 \%$ \\
\hline ChinaDomestic & 11334 & 2992 & 288 & 2992 & $100,00 \%$ & 279 & $96,88 \%$ \\
\hline Russia & 0 & 0 & 0 & 0 & $0,00 \%$ & 0 & $0,00 \%$ \\
\hline TOTAL & 18301902 & 2692976 & 413144 & 2692976 & $93,33 \%$ & 409978 & $91,32 \%$ \\
\hline
\end{tabular}

Table 5.b Number of "Likes", "Shares" and "Comments" by the selected 7 NTOs and their users in 2013-2015.

\begin{tabular}{|c|c|c|c|c|c|c|c|}
\hline \multirow[b]{2}{*}{ Country } & \multicolumn{3}{|c|}{ Performed by NTOs and users } & \multicolumn{4}{|c|}{ Performed by users only } \\
\hline & \#Likes (L) & \#Shares (S) & \#Comments (C) & \#Shares (SU) & $\% S U / S$ & \#Comments (CU) & $\% \mathrm{CU} / \mathrm{C}$ \\
\hline UnitedKingdom & 5070838 & 647937 & 105654 & 647937 & $100,00 \%$ & 105335 & $99,70 \%$ \\
\hline Turkey & 4541343 & 533333 & 67571 & 533333 & $100,00 \%$ & 67571 & $100,00 \%$ \\
\hline Italy & 3114870 & 820588 & 79099 & 820588 & $100,00 \%$ & 78621 & $99,40 \%$ \\
\hline SpainDomestic & 2702193 & 402459 & 58147 & 402459 & $100,00 \%$ & 57927 & $99,62 \%$ \\
\hline Mexico & 1426346 & 141512 & 34944 & 141512 & $100,00 \%$ & 34868 & $99,78 \%$ \\
\hline GermanyDomestic & 329066 & 33492 & 7029 & 33492 & $100,00 \%$ & 6178 & $87,89 \%$ \\
\hline FranceDomestic & 228942 & 30241 & 11917 & 30241 & $100,00 \%$ & 11761 & $98,69 \%$ \\
\hline TOTAL & 17413598 & 2609562 & 364361 & 2609562 & $100,00 \%$ & 362261 & $97,87 \%$ \\
\hline
\end{tabular}


Table 6. Overall number of Facebook Fans and change, 2013-2015.

\begin{tabular}{lrrr} 
NTO/Country & \#Fans (Start of 2013) & \#Fans (End of 2015) & Change(\%) \\
United Kingdom & $1,125,763$ & $2,239,153$ & $98.90 \%$ \\
Mexico & $1,051,084$ & $2,138,118$ & $103.42 \%$ \\
Spain Domestic & 759,568 & 189,604 & $-75.04 \%$ \\
Germany Domestic & 430,815 & 403,277 & $-6.39 \%$ \\
France Domestic & 31,080 & 71,658 & $130.56 \%$ \\
Italy & 18,568 & 272,056 & $1365.19 \%$ \\
Turkey & 0 & $2,010,684$ & $\mathrm{NA}$ \\
\hline Overall Total & $\mathbf{3 , 4 1 6 , 8 7 8}$ & $\mathbf{7 , 3 2 4 , 5 5 0}$ & \\
\hline
\end{tabular}


Table 7 - Descriptive statistics and correlations

\begin{tabular}{lrrrrrrr}
\hline & \multicolumn{1}{c}{ Mean } & Std dev & \multicolumn{1}{c}{1} & \multicolumn{1}{c}{2} & 3 & 4 & 5 \\
\hline 1.Photo & 75.635 & 21.104 & & & & & \\
2.Post frequency & 4.024 & 4.509 & -.084 & & & & \\
3.Morning posts & 28.439 & 18.908 & .085 & .098 & & & \\
4.Evening posts & 18.537 & 16.740 & .107 & $.252^{* *}$ & $-.340^{* *}$ & & \\
5.Night posts & 3.103 & 3.659 & .012 & $.411^{* *}$ & $.273^{* *}$ & -.035 & \\
6.Weekend posts & 21.658 & 8.246 & $.346^{* *}$ & .076 & -.021 & .002 & -.105 \\
\hline
\end{tabular}

Notes: ${ }^{* *} \mathrm{p}<.05 ;{ }^{* * *} \mathrm{p}<.01$

$\mathrm{N}=203$ 
Table 8 - Results of multivariate regressions using panel data analysis

\begin{tabular}{|c|c|c|}
\hline Independent variable & b coefficient & Std error \\
\hline 1.Photo & $7.45^{*}$ & 3.07 \\
\hline 2.Post frequency & 41.27 & 27.69 \\
\hline 3.Morning posts & 5.82 & 4.77 \\
\hline 4.Evening posts & $-8.68 *$ & 4.17 \\
\hline 5.Night posts & 17.14 & 14.74 \\
\hline 6.Weekend posts & $13.48^{*}$ & 6.43 \\
\hline 7. Constant & $-626.67 * *$ & 223.84 \\
\hline $\mathrm{R}^{2}$ (within) & .16 & \\
\hline $\mathrm{R}^{2}$ (between) & .14 & \\
\hline $\mathrm{F}$ & $(6,190)=6.13^{* * *}$ & \\
\hline
\end{tabular}

$\mathrm{N}=203$; Groups $=7$

Note: ${ }^{*} \mathrm{p}<.05 ;{ }^{* *} \mathrm{p}<.01$ 